\title{
APPLICATION OF RIGID LINKS IN STRUCTURAL DESIGN MODELS
}

\author{
Sergey Yu. Fialko \\ Cracow University of Technology, Cracow, POLAND
}

\begin{abstract}
A special finite element modelling rigid links is proposed for the linear static and buckling analysis. Unlike the classical approach based on the theorems of rigid body kinematics, the proposed approach preserves the similarity between the adjacency graph for a sparse matrix and the adjacency graph for nodes of the finite element model, which allows applying sparse direct solvers more effectively. Besides, the proposed approach allows significantly reducing the number of nonzero entries in the factored stiffness matrix in comparison with the classical one, which greatly reduces the duration of the solution. For buckling problems of structures containing rigid bodies, this approach gives correct results. Several examples demonstrate its efficiency.
\end{abstract}

Keywords: finite element method, rigid bodies, rigid links, buckling analysis, multistory buildings

\section{ПРИМЕНЕНИЕ ЖЕСТКИХ ВСТАВОК В РАСЧЕТНЫХ МОДЕЛЯХ КОНСТРУКЦИЙ}

\author{
С.Ю. Фиалко \\ Краковский политехнический университет им. Тадеуша Костюшко, г. Краков, ПОЛЬША
}

\begin{abstract}
Аннотация: В настоящей статье предлагается специализированный подход к моделированию жестких вставок в рамках метода конечных элементов (МКЭ) при решении линейных статических задач и задач анализа устойчивости конструкций. В отличие от известного классического подхода, основанного на теоремах кинематики твердого тела, предлагаемый подход сохраняет сходство между графом смежности для разреженной матрицы и графом смежности для узлов конечноэлементной модели, что позволяет более эффективно применять прямые решатели для разреженных матриц. Кроме того, предлагаемый подход позволяет значительно уменьшить количество ненулевых записей в факторизованной матрице жесткости по сравнению с соответствующим классическим, что значительно сокращает объем вычислительной работы и соответственно время счета. Для задач расчета конструкций, содержащих абсолютно твердые (недеформируемые) тела, на устойчивость предлагаемый подход также позволяет получить корректные результаты. Несколько примеров демонстрируют эффективность предлагаемого подхода.
\end{abstract}

Ключевые слова: метод конечных элементов, абсолютно твердые тела, жесткие вставки, анализ устойчивости конструкций, многоэтажные здания

\section{INTRODUCTION}

Rigid links are widely used in structural design models. A rigid link usually refers to a kinematic relationship between the selected nodes of the finite element model, when the stiffness values of the structural elements connecting them are considered to be many times larger than those of other elements due to a number of considerations.
Let several nodes $S_{1}, S_{2}, \ldots, S_{n}$ be connected by rigid links with a node $\mathrm{M}$. The node $\mathrm{M}$ is a master node, and the nodes $S_{i}, i \in[1, n]$ are slave nodes (Fig. 1).

Then on the basis of the theorem of rigid body kinematics

$$
\left(\begin{array}{l}
\mathbf{u}_{S i} \\
\boldsymbol{\theta}_{S i}
\end{array}\right)=\left(\begin{array}{c}
\mathbf{u}_{M}+\boldsymbol{\theta}_{M} \times \boldsymbol{\rho}_{M-S i} \\
\boldsymbol{\theta}_{M}
\end{array}\right), \quad i \in[1, n],
$$


where $\mathbf{u}_{M}, \mathbf{u}_{S i}$ are vectors of translational displacements of the nodes $\mathrm{M}, \mathrm{S}_{\mathrm{i}}$ respectively, $\boldsymbol{\theta}_{\mathrm{M}}, \boldsymbol{\theta}_{\mathrm{Si}}$ are vectors of rotation angles, $\boldsymbol{\rho}_{\mathrm{M}-\mathrm{Si}}$ is a radius-vector connecting the node $\mathrm{M}$ with a node $S_{\mathrm{i}}$.

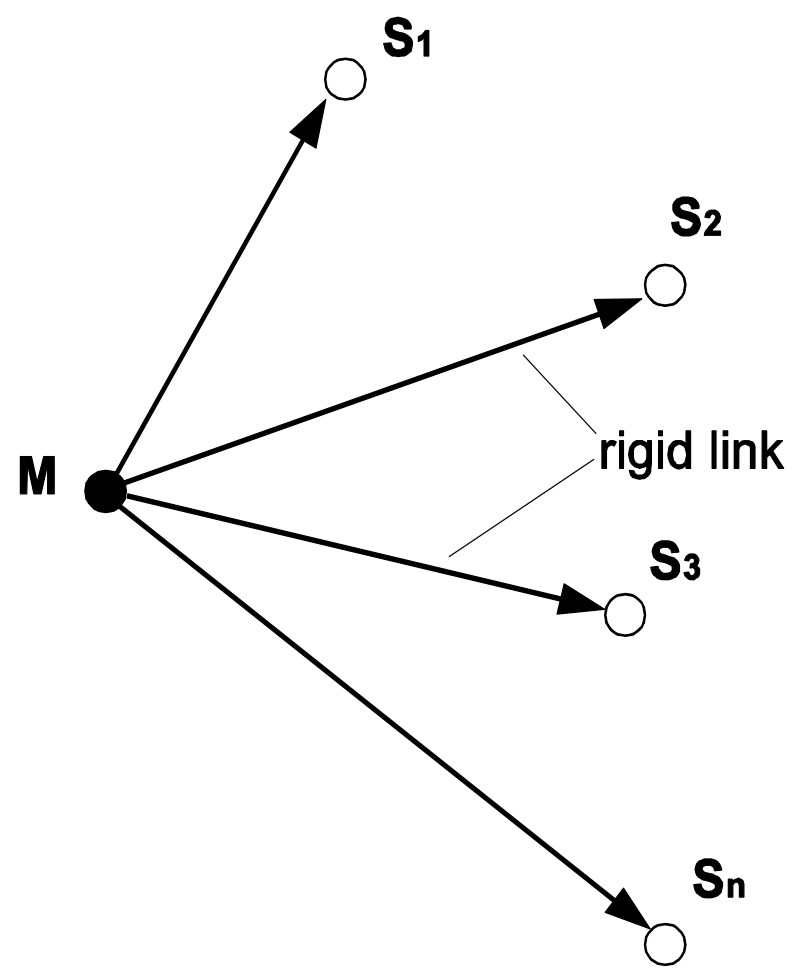

Figure 1. Model of a rigid body consisting of $s$ system of rigid links. $M$ is a master node, $S$ is a slave node.

Thus, displacements and rotation angles of all nodes $S_{i}, i \in[1, n]$, are expressed through the respective displacements and rotation angles of the node $\mathrm{M}$.

A set of nodes $M \cup S_{i}, i \in[1, n]$ and a set of rigid links $\left\{M, S_{i}\right\} \quad i \in[1, n]$, each of which connects the node $M$ to a node $S_{i}, i \in[1, n]$, form a rigid body.

In some cases, the binding of the node $S_{i}$ to the node $\mathrm{M}$ does not take place for all degrees of freedom, but only for some of them. The displacements of unbound degrees of freedom of all slave nodes are independent variables, and all displacements of bound degrees of freedom are expressed through the displacements and rotation angles of the master node. In this case, a rigid body is not formed, and an incomplete binding takes place.

In many FEA software, the use of rigid links leads to the fact that the slave nodes with the bound degrees of freedom obtain numbers of the corresponding equations of the master node.

Let us consider an example presented in Fig. 2. The equilibrium equation of a finite element with rigid links imposed on its nodes is transformed as follows:

$$
\mathbf{Q}_{e}^{T} \mathbf{K}_{e} \mathbf{Q}_{e} \tilde{\mathbf{q}}_{e}=\mathbf{Q}_{e}^{T} \mathbf{r}_{e}
$$

where

$$
\begin{aligned}
& \mathbf{K}_{e}=\left(\begin{array}{llll}
\mathbf{K}_{i i} & \mathbf{K}_{i j} & \mathbf{K}_{i p} & \mathbf{K}_{i q} \\
\mathbf{K}_{j i} & \mathbf{K}_{j j} & \mathbf{K}_{j p} & \mathbf{K}_{j q} \\
\mathbf{K}_{p i} & \mathbf{K}_{p j} & \mathbf{K}_{p p} & \mathbf{K}_{p q} \\
\mathbf{K}_{q i} & \mathbf{K}_{q j} & \mathbf{K}_{q p} & \mathbf{K}_{q q}
\end{array}\right), \\
& \mathbf{Q}_{e}=\left(\begin{array}{ccc}
\mathbf{C}_{i, M_{1}} & 0 & 0 \\
0 & 0 & \mathbf{I} \\
\mathbf{C}_{p, M_{1}} & 0 & 0 \\
0 & \mathbf{C}_{q, M_{2}} & 0
\end{array}\right), \\
& \mathbf{q}_{e}=\left(\begin{array}{l}
\vec{U}_{i} \\
\vec{U}_{j} \\
\vec{U}_{p} \\
\vec{U}_{q}
\end{array}\right), \quad \mathbf{q}_{e}=\mathbf{Q}_{e} \tilde{\mathbf{q}}_{e}, \\
& \tilde{\mathbf{q}}_{e}=\left(\begin{array}{l}
\vec{U}_{M_{1}} \\
\vec{U}_{M_{2}} \\
\vec{U}_{j}
\end{array}\right), \quad \mathbf{r}_{e}=\left(\begin{array}{l}
\vec{R}_{i} \\
\vec{R}_{j} \\
\vec{R}_{p} \\
\vec{R}_{q}
\end{array}\right),
\end{aligned}
$$

$\mathbf{K}_{\mathrm{mn}}-$ block of the stiffness matrix corresponding to the nodes $m, n$, $\overrightarrow{\mathrm{U}}_{\mathrm{m}}^{\mathrm{T}}=\left(\begin{array}{ll}\mathbf{u}_{\mathrm{m}} & \boldsymbol{\theta}_{\mathrm{m}}\end{array}\right), \quad \overrightarrow{\mathrm{R}}_{\mathrm{m}}^{\mathrm{T}}=\left(\begin{array}{ll}\overrightarrow{\mathrm{F}}_{\mathrm{m}} & \overrightarrow{\mathrm{M}}_{\mathrm{m}}\end{array}\right), \quad \mathbf{u}_{\mathrm{m}}, \boldsymbol{\theta}_{\mathrm{m}}-$ vectors of the translational displacements and rotation angles in the node $\mathrm{m}, \overrightarrow{\mathrm{F}}_{\mathrm{m}}, \overrightarrow{\mathrm{M}}_{\mathrm{m}}$ - total force and total moment in the node $\mathrm{m}$, 


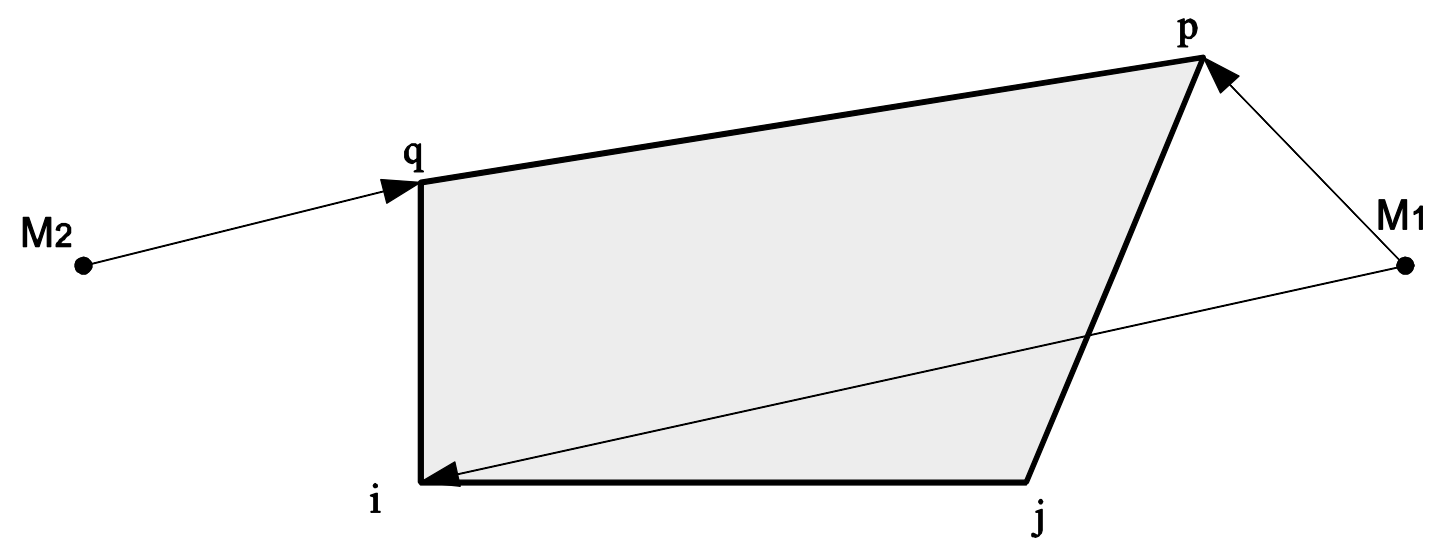

Figure 2. Four-node shell finite element with imposed rigid links. $M_{1}, M_{2}$ are master nodes.

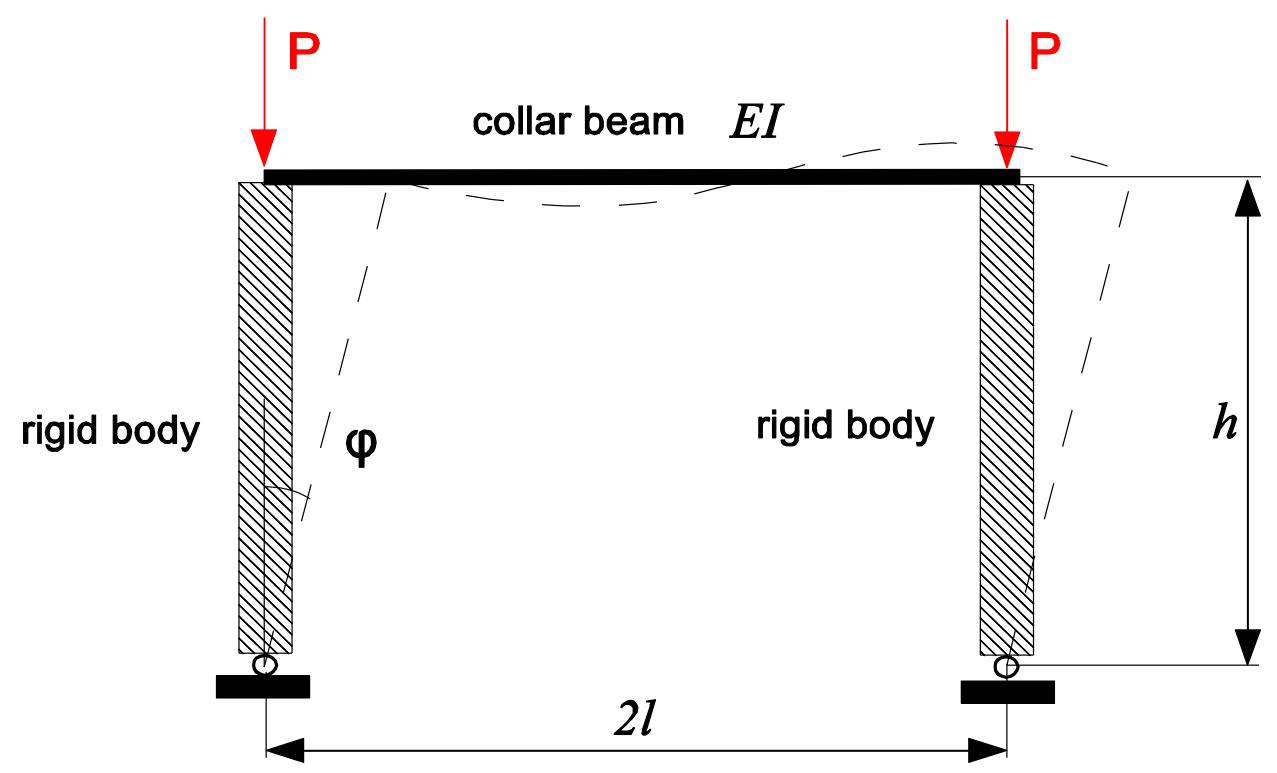

Figure 3. Design model of a plane frame with rigid columns. Dashed line shows the buckling mode.

$$
\begin{gathered}
\mathbf{C}_{\mathrm{m}, \mathrm{M}}=\left(\begin{array}{cc}
\mathbf{I} & \mathbf{F}_{\mathrm{M}, \mathrm{m}} \\
0 & \mathbf{I}
\end{array}\right), \\
\mathbf{F}_{\mathrm{M}, \mathrm{m}}=\left(\begin{array}{ccc}
0 & \rho_{\mathrm{z}} & -\rho_{\mathrm{y}} \\
-\rho_{\mathrm{z}} & 0 & \rho_{\mathrm{x}} \\
\rho_{\mathrm{y}} & -\rho_{\mathrm{x}} & 0
\end{array}\right),
\end{gathered}
$$

$\rho_{\mathrm{x}}, \rho_{\mathrm{y}}, \rho_{\mathrm{z}}-$ components of a vector connecting the master node $\mathrm{M}$ with the slave node $\mathrm{m}$.

In the result of the transformation the expression (2) becomes

$$
\tilde{\mathbf{K}}_{e} \tilde{\mathbf{q}}_{e}=\tilde{\mathbf{r}}_{e},
$$

where $\mathbf{r}_{\mathrm{e}}=\mathbf{Q}_{\mathrm{e}}^{\mathrm{T}} \mathbf{r}_{\mathrm{e}}-$ the result of the parallel transfer of the forces from the slave nodes to the respective master nodes. Let's call this approach method "A".

Typical examples of the use of rigid links are given in Fig. 3 - 6. Fig. 3 shows a design model of a plane frame with infinitely rigid columns.

It turned out that many of the FEA software solve the buckling problem for systems with rigid links incorrectly 1 . We shall return to this problem later. 


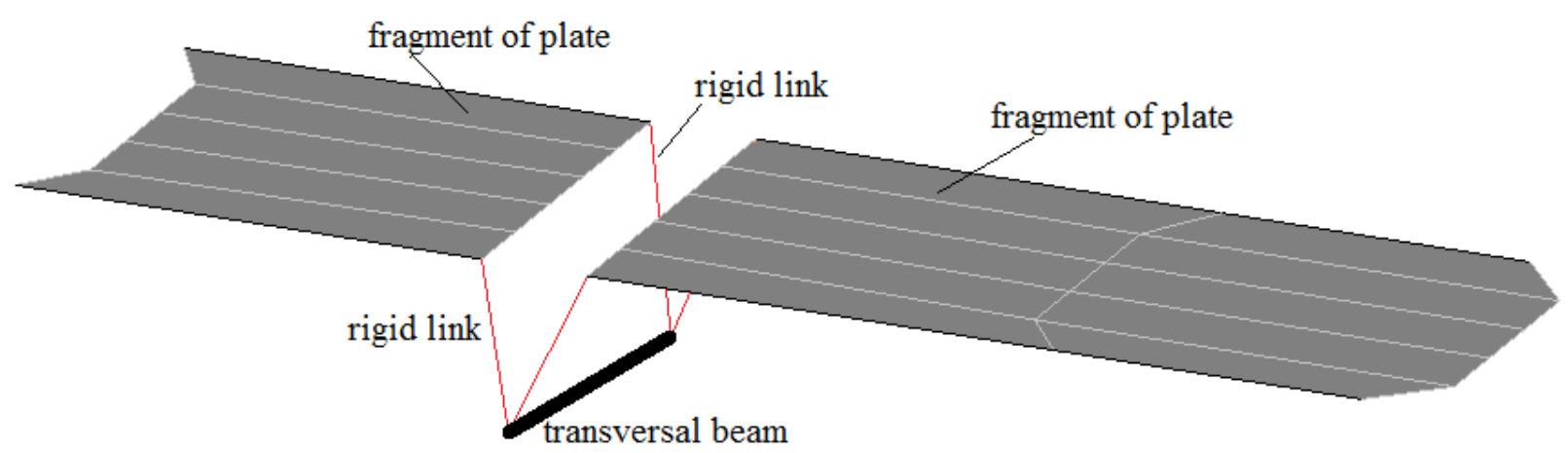

Figure 4. Attachment of bearing slabs of the bridge span to the transverse beam at the junction of two spans.

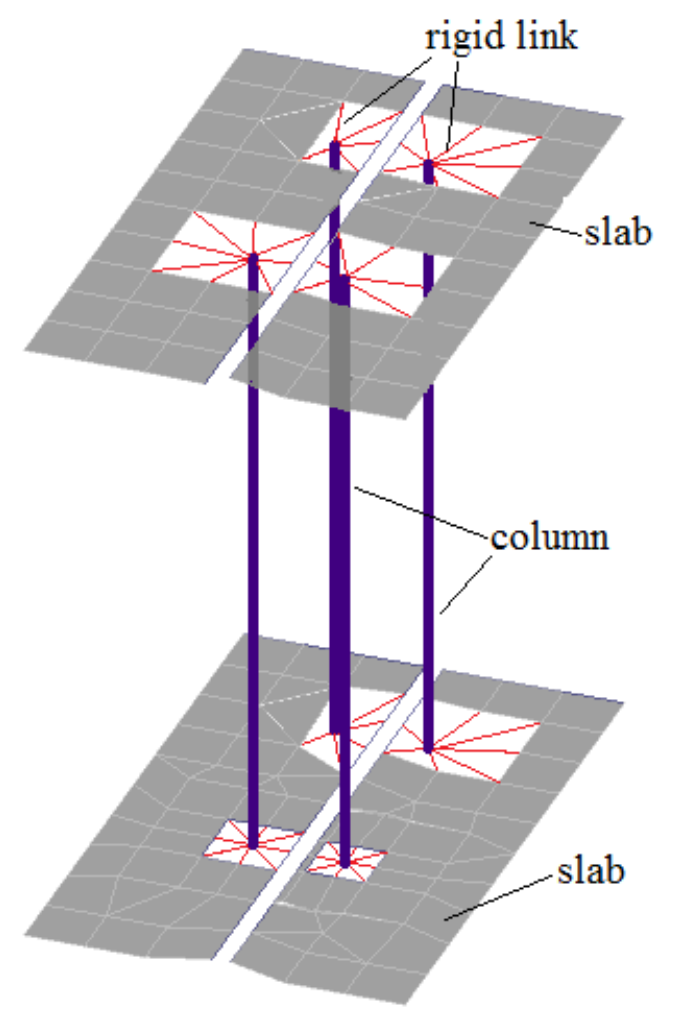

Figure 5. Connection of columns with floor slabs. Rigid links form a rigid body in order to prevent an unrestricted increase of bending moments and transverse forces in the slab with the mesh refinement.

Fig. 4 shows a fragment of the span structure of the bridge. A detailed modeling of some joints and connections often turns out to be unnecessary. However, in order to create a design model that adequately reflects the behavior of the structure, it is necessary to impose a series of rigid links on the nodes.
Fig. 5 shows a fragment of the connection of columns with floor slabs where the columns are modelled by bars and the slabs - by flat shell finite elements.

When the Kirchhoff - Love theory of thin shells is used, bending moments tend to infinity at the point of application of the concentrated force column reaction directed along its axis. 


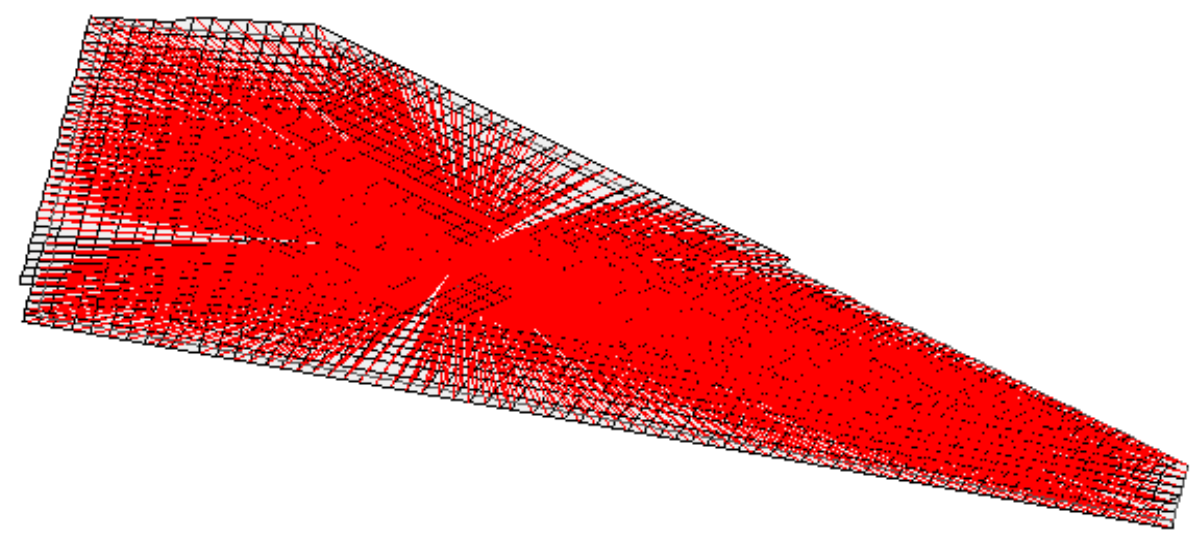

Figure 6. Imposed rigid links make the floor slab of a high-rise building rigid in its plane, however, the bending stiffness value remains finite.

In order to justify this fact, simply select a circular plate in the vicinity of the column-toslab junction point and apply the known solution of the problem of a circular plate subjected to a concentrated force applied at its center 2. It is known that for such a problem the radial bending moment in the center of the plate has a logarithmic singularity.

It follows that in the process of mesh refinement there is an unlimited increase in the values of bending moments in the shell in a column-toslab junction point 1 . In order to study the stress-strain state in the vicinity of this point, you should separately consider this joint using a $3 \mathrm{D}$ model for both the column and the slab. It is impossible to solve this problem within the thin shell theory. Therefore in order to avoid singularity in the solution, various approaches are used.

One of them lies in imposing rigid links on the adjacent nodes, the column-to-slab joint being the master node. Thus, a rigid body is formed, the size of which according to the SaintVenant's principle is about two cross-sectional heights, and the area adjacent to a singular point is excluded from the stress analysis. It should be noted that when the Mindlin-Reissner shell theory is used, this peculiarity remains.

The seismic codes in many cases suggest using design models with floor slabs rigid in their plane, their bending stiffness having a finite value. Implementation of such a design model is achieved by imposing links rigid only in the plane of the floor slab (Fig. 6).

A peculiarity of this problem is a large number of rigid links meeting in each master node. At the same time, the binding of distant nodes takes place. When the " $\mathrm{A}$ " method is used, it leads to a significant increase in the number of nonzero entries in the factored stiffness matrix, despite the fact that the number of equations decreases when the rigid links are imposed.

Even when the dimension of the problem is relatively small, the duration of the solution increases significantly. The following example confirms this.

The drawback of the " $\mathrm{A}$ " method is also the lack of similarity between the adjacency graph for nodes of the finite element model and the adjacency graph for a sparse matrix.

Many finite element solvers use this similarity, which enables to reorder the adjacency graph for nodes, and then to use the fact that each node of the finite element model contains a group of equations which forms a dense submatrix in the sparse matrix $3,4,5$. The reordering of the nodal adjacency graph is carried out several times faster than that of the adjacency graph for the sparse matrix, and when a coarser graph is used, the number of fill-in usually turns out to be somewhat smaller, than in the case of a more detailed graph 7 . 


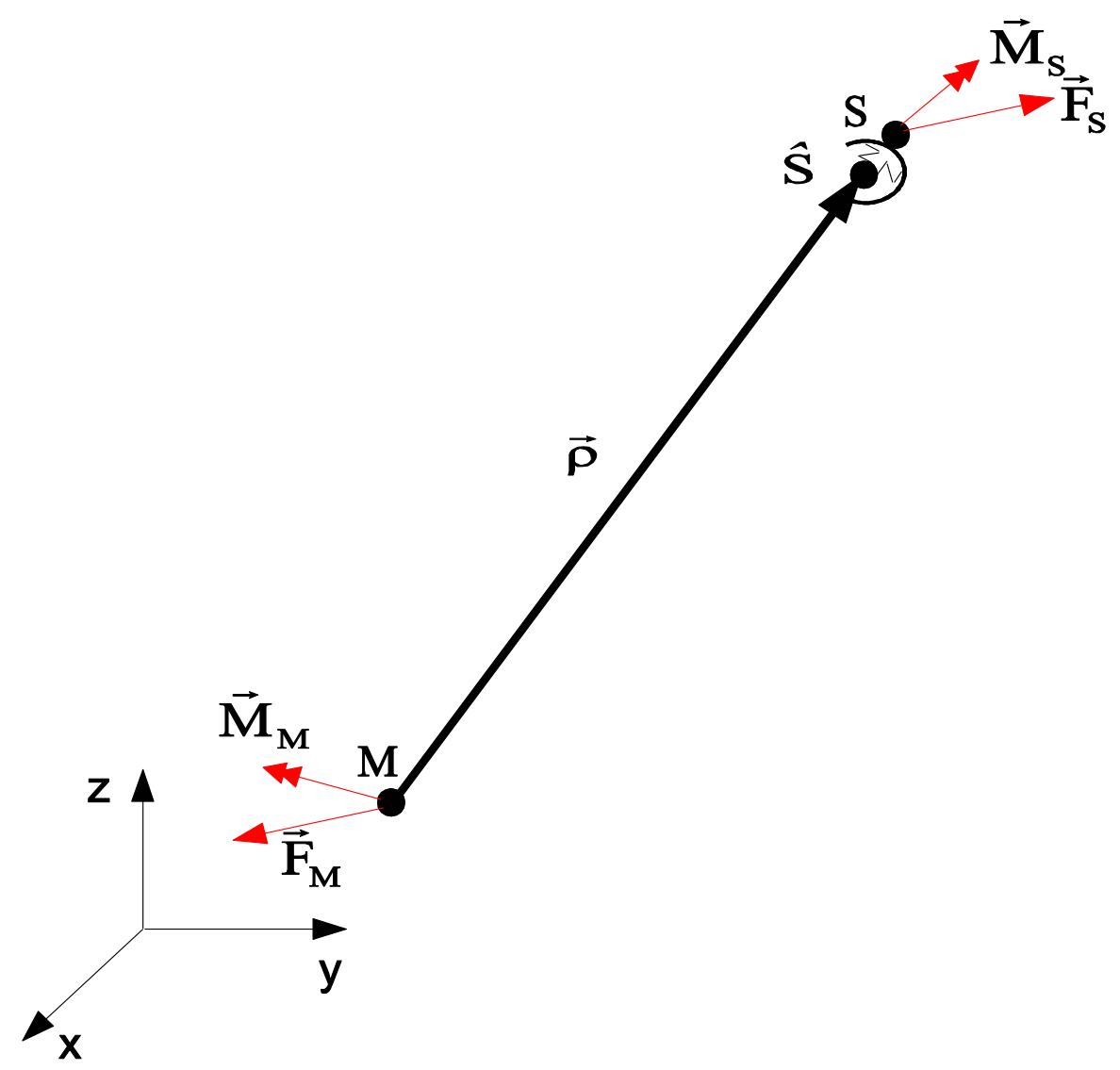

Figure 7. Rlink finite element modelling a rigid link.

Moreover, the initial division of the sparse matrix into dense submatrices enables to optimize the procedure of their combining into larger blocks, which simplifies the use of highperformance procedures for dense matrices and improves their performance.

It should also be noted that the implementation of the "A" method is rather difficult, because the load and displacement vectors, as well as the stiffness matrix of the finite element have to be converted in accordance with the expressions (1) - (3) in different program modules usually developed by different programmers.

This paper proposes a two-node finite element which models a rigid link and preserves the similarity between the nodal adjacency graph and the adjacency graph for the sparse matrix which enables to apply the above-mentioned high-performance finite element solvers to such models without any changes. This approach, which we will call the " $\mathrm{B}$ " method, is much easier to implement than the "A" method because the imposition of rigid links comes down to simply adding the appropriate finite elements to the design model.

\section{LINEAR STATICS}

Fig. 7 shows the proposed Rlink finite element modelling a rigid link.

The element has two nodes - M (master) and $\mathrm{S}$ (slave), connected by a rigid link. The intermediate node $\hat{\mathrm{S}}$ with the same coordinates as the node $\mathrm{S}$ is entered.

Displacements of nodes $S, \hat{S}$ are combined for the bound degrees of freedom. The penalty function method is applied for this purpose. The displacements of all nodes are represented in the global coordinate system OXYZ. The vectors of total forces and total moments $\overrightarrow{\mathrm{F}}_{\mathrm{M}}, \overrightarrow{\mathrm{M}}_{\mathrm{M}}, \overrightarrow{\mathrm{F}}_{\mathrm{S}}, \overrightarrow{\mathrm{M}}_{\mathrm{S}}$ are applied in the nodes $\mathrm{M}$ and $\mathrm{S}$ respectively. 
The principle of virtual works is used to obtain the stiffness matrix of the Rlink finite element:

$$
\delta\left(\vec{U}_{\hat{S}}-\vec{U}_{S}\right)^{T} \Gamma\left(\vec{U}_{\hat{S}}-\vec{U}_{S}\right)-\delta \vec{U}_{M}^{T} \vec{R}_{M}-\delta \vec{U}_{S}^{T} \vec{R}_{S}=0,
$$

where

$$
\begin{aligned}
& \boldsymbol{\Gamma}=\left(\begin{array}{llllll}
\gamma_{x} & & & & & \\
& \gamma_{y} & & & & \\
& & \gamma_{z} & & & \\
& & & \gamma_{R x} & & \\
& & & & \gamma_{R y} & \\
& & & & & \gamma_{R z}
\end{array}\right) \text {, } \\
& \vec{U}_{S}^{T}=\left(\begin{array}{ll}
\mathbf{u}_{S} & \boldsymbol{\theta}_{S}
\end{array}\right), \quad \vec{U}_{M}^{T}=\left(\begin{array}{ll}
\mathbf{u}_{M} & \boldsymbol{\theta}_{M}
\end{array}\right) \\
& \vec{R}_{S}^{T}=\left(\begin{array}{ll}
\vec{F}_{S} & \vec{M}_{S}
\end{array}\right), \quad \vec{R}_{M}^{T}=\left(\begin{array}{ll}
\vec{F}_{M} & \vec{M}_{M}
\end{array}\right)
\end{aligned}
$$

$\mathbf{u}_{\mathrm{M}}, \boldsymbol{\theta}_{\mathrm{M}}, \mathbf{u}_{\mathrm{S}}, \boldsymbol{\theta}_{\mathrm{S}}-$ vectors of displacements and rotation angles in the nodes $\mathrm{M}$ and $\mathrm{S}$ respectively, $\gamma_{x}, \gamma_{y}, \gamma_{z}, \gamma_{R x}, \gamma_{R y}, \gamma_{R z}-$ penalty parameters for displacements in the directions $\mathrm{OX}, \mathrm{OY}, \mathrm{OZ}$ and rotation angles relative to the axes OX, OY, OZ. If the given degree of freedom is not related to the displacements or rotations of the node $\mathrm{M}$, the corresponding penalty parameter is equal to zero.

The matrix $\Gamma$ is diagonal and is presented for a spatial design model with 6 degrees of freedom in a node -3 displacements and 3 rotation angles. The first term in (4) represents the virtual work of the elastic links with the rigidity $2 \cdot \gamma$ on the difference of the displacements of the nodes $\mathrm{S}$ and $\hat{\mathrm{S}}$, where $\gamma$ takes the values of one of the diagonal elements of the matrix $\boldsymbol{\Gamma}$ depending on the degree of freedom this displacement corresponds to. The greater the value of $\gamma$, the less the difference between the displacements (rotations) of the nodes $\mathrm{S}$ and $\hat{\mathrm{S}}$. The remaining terms in (4) represent the virtual work of the external forces applied to the nodes $\mathrm{M}$ and $\mathrm{S}$.

Let us eliminate the displacements $\vec{U}_{S}^{T}$ from (4) using the relations (1):

$$
\begin{aligned}
& \vec{U}_{\hat{S}}=\mathbf{C}_{M \hat{S}} \vec{U}_{M}, \quad \mathbf{C}_{M \hat{S}}=\left(\begin{array}{cc}
\mathbf{I} & \mathbf{F}_{M \hat{S}} \\
0 & \mathbf{I}
\end{array}\right), \\
& \mathbf{F}_{M \hat{S}}=\left(\begin{array}{ccc}
0 & \rho_{z} & -\rho_{y} \\
-\rho_{z} & 0 & \rho_{x} \\
\rho_{y} & -\rho_{x} & 0
\end{array}\right),
\end{aligned}
$$

where $\rho_{x}, \rho_{y}, \rho_{z}-$ projections of the vector $\vec{\rho}$ onto the axes of the global coordinate system. Substitute (5) into (4):

$$
\begin{aligned}
\delta\left(\mathbf{C}_{M \hat{S}} \vec{U}_{M}-\vec{U}_{S}\right)^{T} \Gamma\left(\mathbf{C}_{M \hat{S}} \vec{U}_{M}-\vec{U}_{S}\right)- \\
-\delta \vec{U}_{M}^{T} \vec{R}_{M}-\delta \vec{U}_{S}^{T} \vec{R}_{S}=0
\end{aligned}
$$

or

$$
\begin{aligned}
\delta \vec{U}_{M}^{T}\left(\mathbf{C}_{M \hat{S}}^{T} \boldsymbol{\Gamma} \mathbf{C}_{M \hat{S}} \vec{U}_{M}-\mathbf{C}_{M \hat{S}}^{T} \boldsymbol{\Gamma} \vec{U}_{S}-\vec{R}_{M}\right)+ \\
\quad+\delta \vec{U}_{S}^{T}\left(-\boldsymbol{\Gamma} \mathbf{C}_{M \hat{S}} \vec{U}_{M}+\boldsymbol{\Gamma} \vec{U}_{S}-\vec{R}_{S}\right)=0 .
\end{aligned}
$$

Taking into account the independence of variations $\delta \overrightarrow{\mathrm{U}}_{\mathrm{M}}^{\mathrm{T}}, \delta \overrightarrow{\mathrm{U}}_{\mathrm{S}}^{\mathrm{T}}$ we obtain:

$$
\left\{\begin{array}{l}
\mathbf{C}_{\mathrm{MS}}^{\mathrm{T}} \boldsymbol{\Gamma} \mathbf{C}_{\mathrm{MS}} \overrightarrow{\mathrm{U}}_{\mathrm{M}}-\mathbf{C}_{\mathrm{MS}}^{\mathrm{T}} \boldsymbol{\Gamma} \overrightarrow{\mathrm{U}}_{\mathrm{S}}-\overrightarrow{\mathrm{R}}_{\mathrm{M}}=0 \\
-\Gamma \mathbf{C}_{\mathrm{MS}} \overrightarrow{\mathrm{U}}_{\mathrm{M}}+\Gamma \overrightarrow{\mathrm{U}}_{\mathrm{S}}-\overrightarrow{\mathrm{R}}_{\mathrm{S}}=0
\end{array}\right.
$$

then the equilibrium equation of the Rlink element is as follows:

$$
\mathbf{K}_{\mathrm{e}} \mathbf{q}_{\mathrm{e}}=\mathbf{r}_{\mathrm{e}},
$$

where

$$
\begin{aligned}
\mathbf{K}_{e} & =\left(\begin{array}{cc}
\mathbf{C}_{M \hat{S}}^{T} \boldsymbol{\Gamma} \mathbf{C}_{M \hat{S}} & -\mathbf{C}_{M \hat{S}}^{T} \boldsymbol{\Gamma} \\
-\boldsymbol{\Gamma} \mathbf{C}_{M \hat{S}} & \boldsymbol{\Gamma}
\end{array}\right), \\
\mathbf{q}_{e} & =\left(\begin{array}{l}
\vec{U}_{M} \\
\vec{U}_{S}
\end{array}\right), \quad \mathbf{r}_{e}=\left(\begin{array}{c}
\vec{R}_{M} \\
\vec{R}_{S}
\end{array}\right)
\end{aligned}
$$

and $\mathbf{K}_{\mathrm{e}}$ is the stiffness matrix of the Rlink element. 


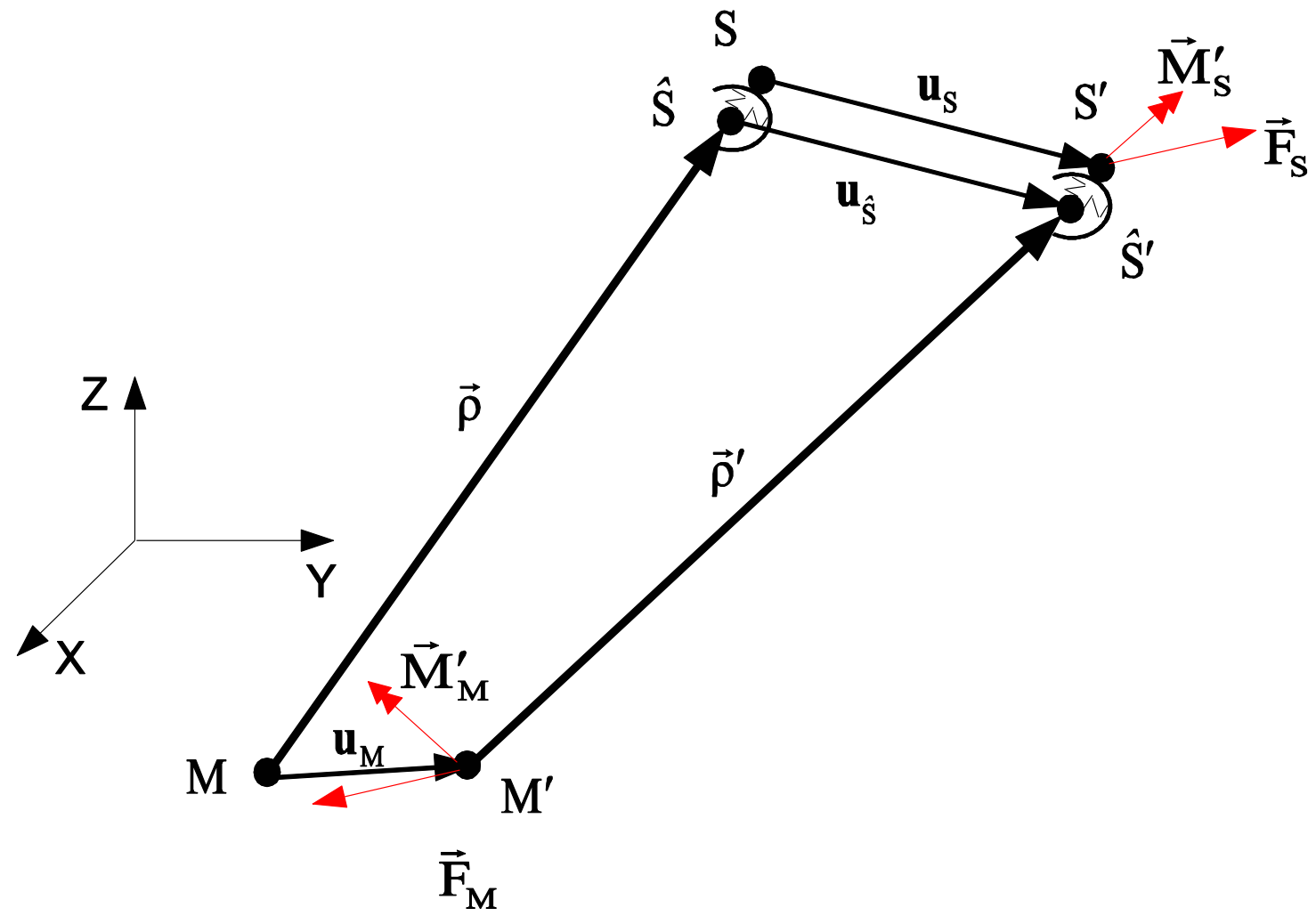

Figure 8. Buckling of the Rlink element.

\section{BUCKLING}

According to the Euler stability criterion the possibility of the existence of the deflected equilibrium state of the Rlink element is looked for, and the load does not change upon the transition to the deflected state. The minimum value of the load parameter, at which the existence of an adjacent equilibrium state becomes possible for the first time, is called critical.

The buckling of the Rlink element is shown in Fig. 8.

The points $M, \hat{S}, S$ correspond to the initial state. The vectors of total forces and total moments $\vec{F}_{M}, \vec{M}_{M}, \vec{F}_{S}, \vec{M}_{S}$, applied to the nodes $\mathrm{M}, \mathrm{S}$, are obtained from the solution of the prebuckling problem. It is assumed that the displacements and the rotation angles are so small in comparison with the geometric dimensions of the structure that the difference of the deformed state in comparison with the initial one can be neglected.

The position of the nodes $M^{\prime}, \hat{S}^{\prime}, S^{\prime}$ defines the deflected state of the Rlink element. The vectors of total forces and moments applied at the nodes $\mathrm{M}, \mathrm{S}$, move to the nodes $\mathrm{M}^{\prime}, \mathrm{S}^{\prime}$ during buckling and $\mathbf{u}_{\mathrm{M}}, \mathbf{u}_{\hat{\mathrm{s}}}, \mathbf{u}_{\mathrm{S}}$ are the respective displacements of the nodes $\mathrm{M}, \hat{\mathrm{S}}, \mathrm{S}$ at buckling. Since the initial buckling is considered, the vectors of total forces and moments $\overrightarrow{\mathrm{F}}_{\mathrm{M}}, \overrightarrow{\mathrm{M}}_{\mathrm{M}}, \overrightarrow{\mathrm{F}}_{\mathrm{S}}, \overrightarrow{\mathrm{M}}_{\mathrm{S}}$ remain the same as in the pre-buckling state. The values of total moments change in the result of the parallel transfer of the total force vectors $\overrightarrow{\mathrm{F}}_{\mathrm{M}}, \overrightarrow{\mathrm{F}}_{\mathrm{S}}$ from the points $\mathrm{M}, \mathrm{S}$ to $\mathrm{M}^{\prime}, \mathrm{S}^{\prime}$ :

$$
\begin{aligned}
\overrightarrow{\mathrm{M}}_{\mathrm{M}}^{\prime} & =\overrightarrow{\mathrm{M}}_{\mathrm{M}}+\mathbf{u}_{\mathrm{M}} \times \overrightarrow{\mathrm{F}}_{\mathrm{M}} \\
\overrightarrow{\mathrm{M}}_{\mathrm{S}}^{\prime} & =\overrightarrow{\mathrm{M}}_{\mathrm{S}}+\mathbf{u}_{\mathrm{s}} \times \overrightarrow{\mathrm{F}}_{\mathrm{S}} .
\end{aligned}
$$

Since each link connecting the points $\hat{S}^{\prime}$ and $S^{\prime}$ works independently of the others, it follows 
from the condition of their equilibrium that the vectors of total forces and moments $\overrightarrow{\mathrm{F}}_{\mathrm{S}}, \overrightarrow{\mathrm{M}}_{\mathrm{S}}$ can be transferred to the node $\hat{S}^{\prime}$. Then (9) takes the form

$$
\vec{M}_{S}^{\prime}=\vec{M}_{S}+\mathbf{u}_{\hat{S}} \times \vec{F}_{S}
$$

In the case of partial binding for unbound degrees of freedom, it follows from the solution of the static problem that the corresponding forces or moments in the nodes $\mathrm{M}, \mathrm{S}$ are equal to zero. Therefore, expressions (8) - (10) remain in force.

Applying the principle of virtual works and accepting the deflections during buckling as the virtual displacements, we obtain:

$$
\delta\left(\overrightarrow{\mathrm{U}}_{\hat{\mathrm{S}}}-\overrightarrow{\mathrm{U}}_{\mathrm{S}}\right)^{\mathrm{T}} \Gamma\left(\overrightarrow{\mathrm{U}}_{\hat{\mathrm{s}}}-\overrightarrow{\mathrm{U}}_{\mathrm{S}}\right)-\delta \overrightarrow{\mathrm{U}}_{\mathrm{M}}^{\mathrm{T}} \overrightarrow{\mathrm{R}}_{\mathrm{M}}-\delta \overrightarrow{\mathrm{U}}_{\hat{\mathrm{S}}}^{\mathrm{T}} \overrightarrow{\mathrm{R}}_{\mathrm{S}}=0,
$$

where the first term is the work of internal forces of the Rlink element on virtual displacements during buckling and the two last terms are the work of external forces.

Let

$$
\begin{array}{r}
\delta \Pi=\delta\left(\vec{U}_{\hat{s}}-\vec{U}_{S}\right)^{T} \Gamma\left(\vec{U}_{\hat{s}}-\vec{U}_{S}\right), \\
\delta W=-\delta \vec{U}_{M}^{T} \vec{R}_{M}-\delta \vec{U}_{\hat{S}}^{T} \vec{R}_{S},
\end{array}
$$

where $\Pi$ in the potential energy accumulated in the elastic links, $\mathrm{W}$ is the change in the potential of the external forces. It follows from the previous section that

$$
\begin{gathered}
\delta \Pi=\delta \mathbf{q}_{e}^{T} \mathbf{K}_{e} \mathbf{q}_{e}, \\
\delta \mathrm{W}=-\delta\left(\begin{array}{ll}
\mathbf{u}_{\mathrm{M}} & \boldsymbol{\theta}_{\mathrm{M}}
\end{array}\right)\left(\begin{array}{c}
\overrightarrow{\mathrm{F}}_{\mathrm{M}} \\
\overrightarrow{\mathrm{M}}_{\mathrm{M}}^{\prime}
\end{array}\right)-\delta\left(\begin{array}{cc}
\overrightarrow{\mathbf{u}}_{\mathrm{s}} & \boldsymbol{\theta}_{\hat{\mathrm{s}}}
\end{array}\left(\begin{array}{c}
\overrightarrow{\mathrm{F}}_{\mathrm{S}} \\
\overrightarrow{\mathrm{M}}_{\mathrm{S}}^{\prime}
\end{array}\right) .\right.
\end{gathered}
$$

Substituting (1), (8), (10) into (14), we derive:

$$
\begin{aligned}
& \delta W=-\delta\left(\begin{array}{ll}
\mathbf{u}_{M} & \boldsymbol{\theta}_{M}
\end{array}\right)\left(\begin{array}{c}
\vec{F}_{M} \\
\vec{M}_{M}+\mathbf{u}_{M} \times \vec{F}_{M}
\end{array}\right)- \\
& -\delta\left(\mathbf{u}_{M}+\boldsymbol{\theta}_{M} \times \vec{\rho} \quad \boldsymbol{\theta}_{M}\right)\left(\begin{array}{c}
\vec{F}_{S} \\
\vec{M}_{S}+\mathbf{u}_{\hat{S}} \times \vec{F}_{S}
\end{array}\right)= \\
& =-\delta \mathbf{u}_{M}(\underbrace{\vec{F}_{M}+\vec{F}_{S}}_{=0})- \\
& -\delta \boldsymbol{\theta}_{M}(\underbrace{\vec{M}_{M}+\vec{M}_{S}+\vec{\rho} \times \vec{F}_{S}}_{=0})- \\
& -\delta \boldsymbol{\theta}_{M}\left(\mathbf{u}_{M} \times \vec{F}_{M}\right)-\delta \boldsymbol{\theta}_{M}\left(\mathbf{u}_{\hat{S}} \times \vec{F}_{S}\right) .
\end{aligned}
$$

Here we use

$$
\begin{aligned}
& \delta\left(\boldsymbol{\theta}_{M} \times \vec{\rho}\right) \vec{F}_{S}=\left(\delta \boldsymbol{\theta}_{M} \times \vec{\rho}\right) \vec{F}_{S}= \\
& =-\left(\vec{\rho} \times \delta \boldsymbol{\theta}_{M}\right) \vec{F}_{S}=\left(\vec{\rho} \times \vec{F}_{S}\right) \delta \boldsymbol{\theta}_{M}=\delta \boldsymbol{\theta}_{M}\left(\vec{\rho} \times \vec{F}_{S}\right)
\end{aligned}
$$

The first two terms of (15) are the equilibrium equations in the pre-buckling state, therefore they are identically equal to zero. The remaining terms of the expression (15) will be as follows:

$$
\begin{aligned}
\delta W=- & \delta \boldsymbol{\theta}_{M}\left(\mathbf{u}_{M} \times \vec{F}_{M}\right)- \\
& \quad-\delta \boldsymbol{\theta}_{M}\left(\frac{1}{2} \mathbf{u}_{\hat{S}} \times \vec{F}_{S}-\frac{1}{2} \vec{F}_{S} \times \mathbf{u}_{\hat{S}}\right) .
\end{aligned}
$$

Substitute (1) into (17):

$$
\begin{aligned}
& \delta W=-\delta \boldsymbol{\theta}_{M}\left(\mathbf{u}_{M} \times \vec{F}_{M}\right)- \\
& -\delta \boldsymbol{\theta}_{M}\left[\frac{1}{2}\left(\mathbf{u}_{M}+\boldsymbol{\theta}_{M} \times \vec{\rho}\right) \times \vec{F}_{S}-\right. \\
& \left.-\frac{1}{2} \vec{F}_{S} \times\left(\mathbf{u}_{M}+\boldsymbol{\theta}_{M} \times \vec{\rho}\right)\right]= \\
& =-\delta \boldsymbol{\theta}_{M}\left[\mathbf{u}_{M} \times(\underbrace{\vec{F}_{M}+\vec{F}_{S}}_{=0})\right]- \\
& -\delta \boldsymbol{\theta}_{M}\left[\frac{1}{2}\left(\boldsymbol{\theta}_{M} \times \vec{\rho} \times \vec{F}_{S}+\boldsymbol{\theta}_{M} \times \vec{F}_{S} \times \vec{\rho}\right)\right] .
\end{aligned}
$$


Calculating the double cross product, we obtain:

$$
\begin{aligned}
& \boldsymbol{\theta}_{\mathrm{M}} \times \vec{\rho} \times \overrightarrow{\mathrm{F}}_{\mathrm{S}}=\boldsymbol{\Omega} \boldsymbol{\theta}_{\mathrm{M}}, \\
& \boldsymbol{\theta}_{\mathrm{M}} \times \overrightarrow{\mathrm{F}}_{\mathrm{S}} \times \vec{\rho}=\boldsymbol{\Omega}^{\mathrm{T}} \boldsymbol{\theta}_{\mathrm{M}},
\end{aligned}
$$

where

$$
\begin{aligned}
& \boldsymbol{\Omega}= \\
& =\left(\begin{array}{ccc}
-\rho_{y} F_{S}^{y}-\rho_{z} F_{S}^{z} & \rho_{x} F_{S}^{y} & \rho_{x} F_{S}^{z} \\
\rho_{y} F_{S}^{x} & -\rho_{x} F_{S}^{x}-\rho_{z} F_{S}^{z} & \rho_{y} F_{S}^{z} \\
\rho_{z} F_{S}^{x} & \rho_{z} F_{S}^{y} & -\rho_{x} F_{S}^{x}-\rho_{y} F_{S}^{y}
\end{array}\right)
\end{aligned}
$$

Finally,

$$
\delta \mathrm{W}=-\delta \boldsymbol{\theta}_{\mathrm{M}}\left\lfloor\frac{1}{2}\left(\boldsymbol{\Omega}+\boldsymbol{\Omega}^{\mathrm{T}}\right) \boldsymbol{\theta}_{\mathrm{M}}\right\rfloor
$$

Substituting (13) and (22) into (12), and then (12) into (11), we obtain

$$
\delta \mathbf{q}_{\mathrm{e}}\left[\left(\mathbf{K}_{\mathrm{e}}-\lambda \mathbf{G}_{\mathrm{e}}\right) \mathbf{q}_{\mathrm{e}}\right]=0
$$

where $\mathbf{G}_{\mathrm{e}}$ - geometric stiffness matrix of the Rlink element:

$$
\mathbf{G}_{\mathrm{e}}=\left(\begin{array}{cccc}
0 & 0 & 0 & 0 \\
0 & \frac{1}{2}\left(\boldsymbol{\Omega}+\boldsymbol{\Omega}^{\mathrm{T}}\right) & 0 & 0 \\
0 & 0 & 0 & 0 \\
0 & 0 & 0 & 0
\end{array}\right), \quad \mathbf{q}_{\mathrm{e}}=\left(\begin{array}{c}
\mathbf{u}_{\mathrm{M}} \\
\boldsymbol{\theta}_{\mathrm{M}} \\
\mathbf{u}_{\mathrm{S}} \\
\boldsymbol{\theta}_{\mathrm{S}}
\end{array}\right) \text {. }
$$

It is assumed that all loads applied to the structure increase in proportion to the parameter $\lambda$, and $\lambda=1$ for the given load value.

In the case of a rigid body, shown in Fig. 1, stiffness matrices (geometric stiffness matrices) are generated for the respective Rlink elements.

\section{PENALTY PARAMETERS}

A wide scatter of the stiffness values for different degrees of freedom is typical for the problems of structural mechanics. For example, the tension-compression stiffness of a plane frame element is several orders of magnitude greater than its bending stiffness.

Therefore, the penalty parameter (stiffness of links between the nodes $\mathrm{S}$ and $\hat{\mathrm{S}}$ ) should be taken separately for each degree of freedom. In addition, if the stiffness values are too large, it can lead to the ill-conditioning of the global stiffness matrix and the loss of accuracy.

The following algorithm is used for the optimal choice of penalty parameters. First, the diagonal DiagRL of the stiffness matrix is obtained for a model that does not contain any Rlink elements. Then, the equation number eqn_M is defined for each degree of freedom dof of the node $M$, and the corresponding element on the main diagonal is D_M[dof] = DiagRL[eqn_M], where dof $\in$ [x, y, z, RX, RY, RZ] are the degrees of freedom corresponding to the translational displacements and the rotation angles of the node $M$. The same is done for the node $S$ : D_S[dof] = DiagRL[eqn_S], where eqn_S is the equation number corresponding to the degree of freedom dof in the node $\mathrm{S}$. We accept $\gamma_{\text {dof }}=$ GAM·max $\{$ D_M[dof], D_S[dof] $\}$, where GAM $\in[100 \div 10000]$. If there is no binding for the degree of freedom dof, the corresponding $\gamma_{\mathrm{dof}}=$ 0 .

This algorithm enables to flexibly determine the penalty parameters for each degree of freedom. We will provide the solution of the model problem shown in Fig. 9.

Here, $\mathrm{EI}=0.2 \mathrm{MNm}^{2}, a=1 \mathrm{~m}, l=9 \mathrm{~m}, \mathrm{M}=$ $0.001 \mathrm{MNm}$. The exact solution of this problem is: $\tilde{w}_{A}=0.0475 \mathrm{~m}, \tilde{\varphi}_{A}=0.005$, where $\tilde{w}_{A}, \tilde{\varphi}_{A}$ are the vertical displacement and the rotation angle in the point $\mathrm{A}$. Table 1 provides the values of $\mathrm{w}_{\mathrm{A}}, \varphi_{\mathrm{A}}$, obtained by the finite element method using the Rlink element and a conventional element of the plane frame with the large finite stiffness $E I^{\prime}$ modelling a rigid body. 


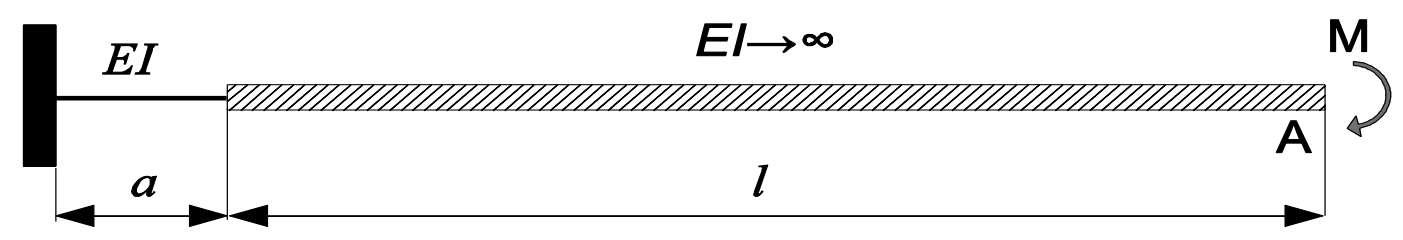

Figure 9. Model problem.

Table 1. Values of the vertical displacement $w_{A}$ and the rotation angle $\varphi_{A}$ in the point A.

\begin{tabular}{|c|c|c|c|c|c|c|c|}
\hline \multicolumn{4}{|c|}{ Rlink element } & \multicolumn{4}{c|}{$\begin{array}{c}\text { Plane frame element } \\
\text { with the large finite stiffness } E I^{\prime}\end{array}$} \\
\hline GAM & $\mathrm{w}_{\mathrm{A}}, \mathrm{m}$ & $\varphi_{\mathrm{A}}$ & Err, \% & $E I^{\prime} / E I$ & $\mathrm{w}_{\mathrm{A}}, \mathrm{m}$ & $\varphi_{\mathrm{A}}$ & $\begin{array}{c}\text { Err, } \\
\%\end{array}$ \\
\hline 10 & $4.750000 \cdot 10^{-2}$ & $5.125000 \cdot 10^{-3}$ & 2.5 & 10 & $6.775000 \cdot 10^{-2}$ & $9.500000 \cdot 10^{-3}$ & 90 \\
\hline 100 & $4.750000 \cdot 10^{-2}$ & $5.012500 \cdot 10^{-3}$ & 0.25 & 100 & $4.952500 \cdot 10^{-2}$ & $5.450000 \cdot 10^{-3}$ & 9 \\
\hline 1000 & $4.750000 \cdot 10^{-2}$ & $5.001250 \cdot 10^{-3}$ & 0.025 & 1000 & $4.770250 \cdot 10^{-2}$ & $5.045000 \cdot 10^{-3}$ & 0.9 \\
\hline 10000 & $4.750000 \cdot 10^{-2}$ & $5.000125 \cdot 10^{-3}$ & $<0.01$ & 10000 & $4.752020 \cdot 10^{-2}$ & $5.004500 \cdot 10^{-3}$ & 0.09 \\
\hline
\end{tabular}

The Err column provides

$$
\operatorname{Err}=100 \cdot \max \left\{\left|\frac{\mathrm{w}_{\mathrm{A}}-\tilde{\mathrm{w}}_{\mathrm{A}}}{\mathrm{w}_{\mathrm{A}}}\right|,\left|\frac{\varphi_{\mathrm{A}}-\tilde{\varphi}_{\mathrm{A}}}{\varphi_{\mathrm{A}}}\right|\right\} \text {. }
$$

When the Rlink element is used, the error is less than $1 \%$ even if GAM $=100$, and when $\mathrm{GAM}=$ 1000 , it is less than $0.1 \%$. When a rigid body is modelled by a plane frame element with the large finite stiffness, in order to achieve an error of less than $0.1 \%$, it is necessary to increase the stiffness by 4 orders of magnitude in comparison with the stiffness of finite elements connected to this rigid body.

Thus, the proposed approach enables to obtain sufficient accuracy for engineering calculations at rather small values of the penalty parameters, which provides insignificant deterioration of conditioning of a global stiffness matrix when using Rlink elements.

The following model problem is given in the Figure 10.

Table 2 compares the number of nonzero entries in the factored stiffness matrix given in megabytes (MB), and the duration of factoring for methods "A" and "B".

The problem is solved on a computer with a 4core processor Intel ${ }^{\circledR}$ Core $^{\mathrm{TM}}$ i7-27600QM CPU
2.4/3.4 GHz, RAM DDR3 8 GB, OS Windows 7 (64 bit) Professional, SP1. A sparse direct solver 8 parallelized by us on the basis of multithreading is used. The values of the maximum displacements for both methods are given in Table 3. METIS reordering 7 is used.

Here $\mathrm{u}, \mathrm{v}, \mathrm{w}$ are displacements along the axes OX, OY, OZ respectively. When the method $\langle\mathrm{B} »$ is used, the stiffness values are summed for all Rlink elements meeting in the master node.

In order to limit the increase of the respective coefficients in the global stiffness matrix, the penalty parameter for all rigid links which make up each rigid body is corrected as follows:

$G A M=$

$=($ GamMax - GamMin $) \cdot \exp \left(-N_{\text {legs }} / 400\right)+$

+ GamMin,

where $\mathrm{N}_{\text {legs }}$ is the number of Rlink elements which make up this rigid body, and the parameters GamMax, GamMin are taken as GamMax $=10$ 000, GamMin $=100$ by default. Thus, the GAM value always lies between GamMax, GamMin, and when the number of rigid links is small, GAM is close in value to GamMax which provides a high accuracy of the 


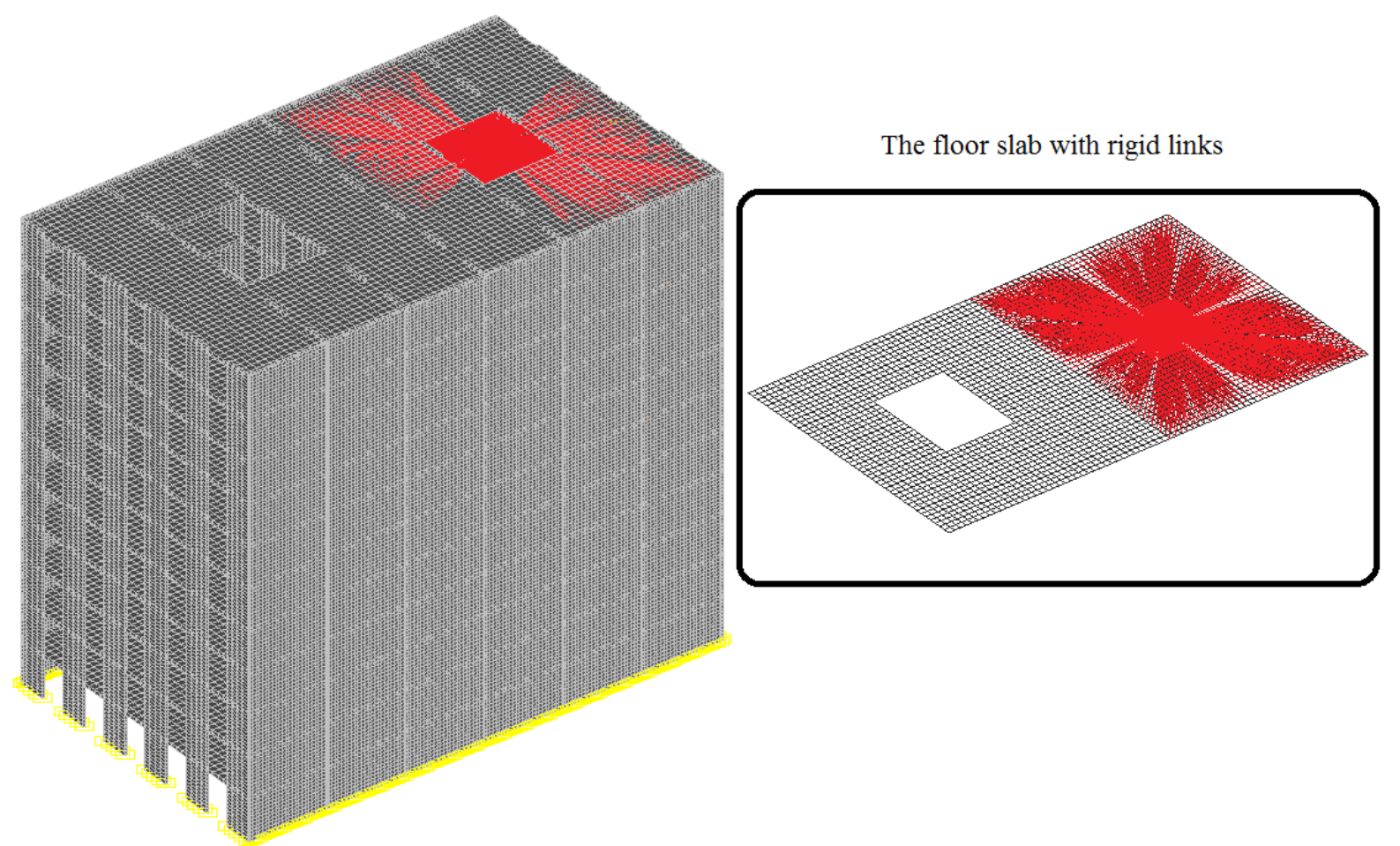

Figure 10. Design model of a multistory building (94 362 nodes, 91811 finite elements). Half of each floor slab is modelled by a rigid body.

Table 2. Comparison of efficiency of methods «A» and «B».

\begin{tabular}{|c|c|c|c|}
\hline $\begin{array}{c}\text { Modeling } \\
\text { of rigid links }\end{array}$ & $\begin{array}{c}\text { Number } \\
\text { of equations }\end{array}$ & $\begin{array}{c}\text { Size of the factored } \\
\text { stiffness matrix, MB }\end{array}$ & $\begin{array}{c}\text { Duration of factoring, } \\
\text { s }\end{array}$ \\
\hline Method «A» & 467292 & 2154 & 195 \\
\hline Method «B» & 563256 & 1304 & 13 \\
\hline
\end{tabular}

Table 3. Maximum displacements $u, v, w$, obtained by methods «A» and «B».

\begin{tabular}{|c|c|c|c|}
\hline Modeling of rigid links & $\max \{\mathrm{u}\}, \mathrm{m}$ & $\max \{\mathrm{v}\}, \mathrm{m}$ & $\max \{\mathrm{w}\}, \mathrm{m}$ \\
\hline Method «A» & $3.295530 \cdot 10^{-4}$ & $7.439050 \cdot 10^{-5}$ & $6.451711 \cdot 10^{-5}$ \\
\hline Method «B» & $3.295534 \cdot 10^{-4}$ & $7.439049 \cdot 10^{-5}$ & $6.451719 \cdot 10^{-5}$ \\
\hline
\end{tabular}

approximation of a rigid body, and when the number of rigid links is large, the GAM value approaches GamMin, reducing the probability of the accuracy loss of the solution due to illconditioning of the stiffness matrix.

The values of maximum displacements obtained by using two different models of rigid links differ from the 6th significant digit. Therefore, we can assume that the results of these two calculations are practically the same. However, the $\langle\mathrm{B} »$ method provided approximately a twofold decrease in the number of nonzero entries in the factored stiffness matrix which led to a reduction of the duration of factoring performed on 4 threads by 15 times.

The results given in this section were obtained with the help of the research software developed by the author.

\section{NUMERICAL RESULTS}

This section describes typical problems of structural mechanics containing rigid links. 


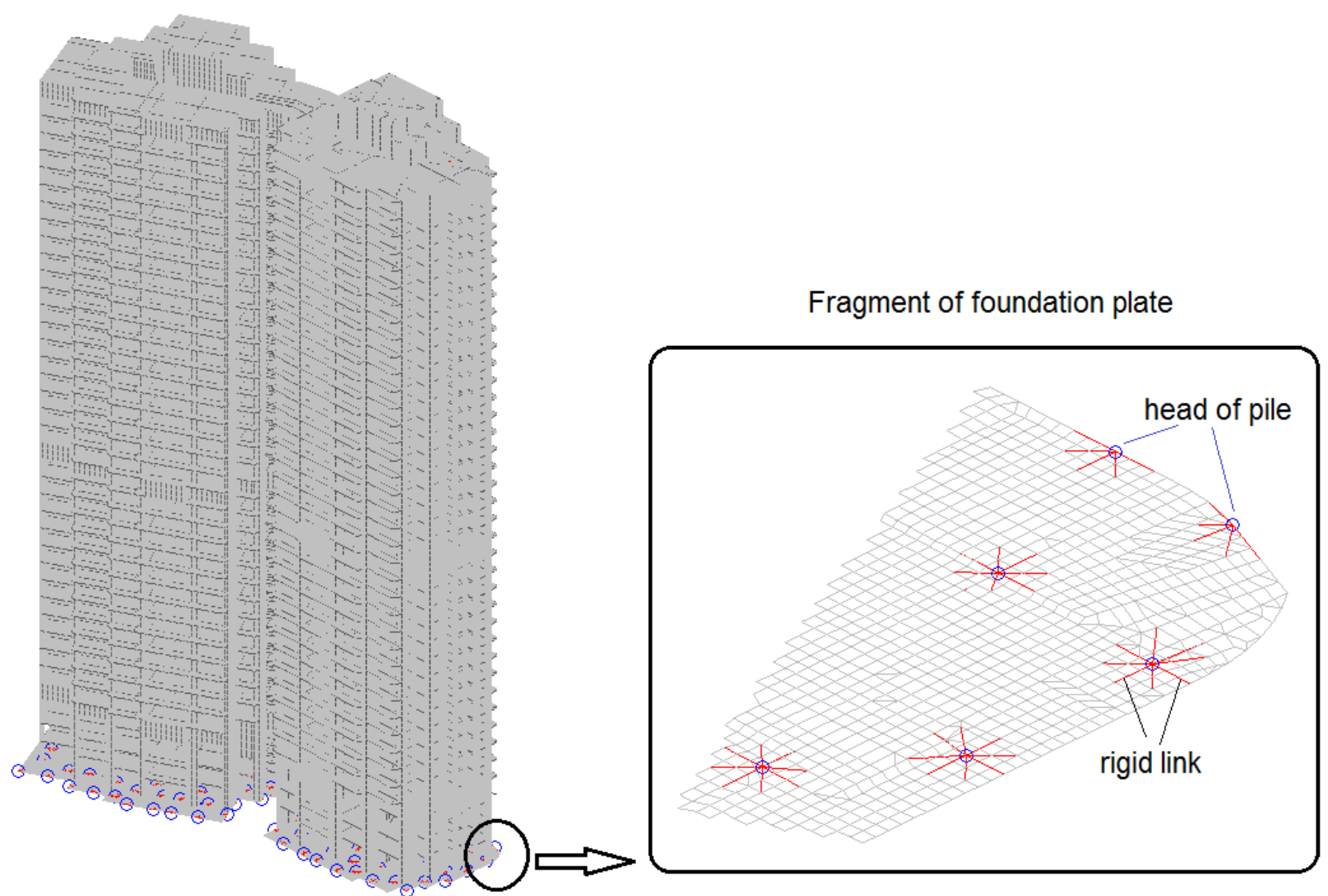

Figure 11. Design model of a multistory building (4 805610 equations) and a fragment of the foundation plate.

The main attention is paid to the accuracy of the numerical solution estimated as follows:

$$
\begin{aligned}
& e r r=\left\|\hat{\mathbf{b}}_{i}-\hat{\mathbf{K}} \hat{\mathbf{x}}_{i}\right\|_{2} /\left\|\hat{\mathbf{b}}_{i}\right\|_{2}, \quad \hat{\mathbf{K}}=\mathbf{D}^{-\frac{1}{2}} \mathbf{K} \mathbf{D}^{-\frac{1}{2}}, \\
& \mathbf{x}_{i}=\mathbf{D}^{-\frac{1}{2}} \hat{\mathbf{x}}_{i}, \quad \hat{\mathbf{b}}_{i}=\mathbf{D}^{-\frac{1}{2}} \mathbf{b}_{i} \quad i \in[1, n r h s],
\end{aligned}
$$

where $\mathbf{b}_{\mathbf{i}}, \mathbf{x}_{\mathbf{i}}, \mathbf{K}, \mathbf{D}$ are respectively the righthand side vector, the solution vector, the stiffness matrix of a system of linear algebraic finite-element equations, the diagonal of this stiffness matrix, $\mathrm{i}$ is the right-hand side number, nrhs is the number of right-hand sides, err is the error measure. When determining $\|. . .\|_{2}$, the dot product of the right-hand side vector $\mathbf{b}_{\mathrm{i}}$ and the residual vector $\hat{\mathbf{b}}_{\mathrm{i}}-\hat{\mathbf{K}} \hat{\mathbf{x}}_{\mathrm{i}}$ is calculated. Since the components of these vectors are values of different dimension (forces and moments of forces), their scaling by a diagonal of the stiffness matrix is carried out.

Example 1. A design model of a multistory building taken from the SCAD Soft ${ }^{1}$ collection is considered. The dimension of the problem is 4805610 equations. The Rlink elements are used in the junctions of the pile heads with the foundation plate to avoid the transfer of concentrated forces to the foundation plate (Fig. 11).

PARFES 5, 6 was used to solve a system of linear algebraic equations with a sparse stiffness matrix K. Despite the fact that the dimension of the design model is large, the accuracy of the solution, shown in Table 4, turned out to be high.

${ }^{1}$ SCAD Soft (www.scadsoft.com) - Software Company, developer of the SCAD finite element modeling software suite, which is used for structural analysis and design, is certified according to building regulations of the CIS countries, and is one of the most popular software applications of the industry in the area. 
Table 4. Error of the solution of the system of linear algebraic equations for the design model given in the example 1.

\begin{tabular}{|c|c|c|c|c|c|c|c|c|}
\hline Load case & 1 & 2 & 3 & 4 & 5 & 6 & 7 & 8 \\
\hline err & $2.2 \cdot 10^{-7}$ & $5.3 \cdot 10^{-8}$ & $3.2 \cdot 10^{-8}$ & $3.6 \cdot 10^{-7}$ & $3.6 \cdot 10^{-7}$ & $3.0 \cdot 10^{-7}$ & $2.0 \cdot 10^{-7}$ & $2.6 \cdot 10^{-7}$ \\
\hline
\end{tabular}

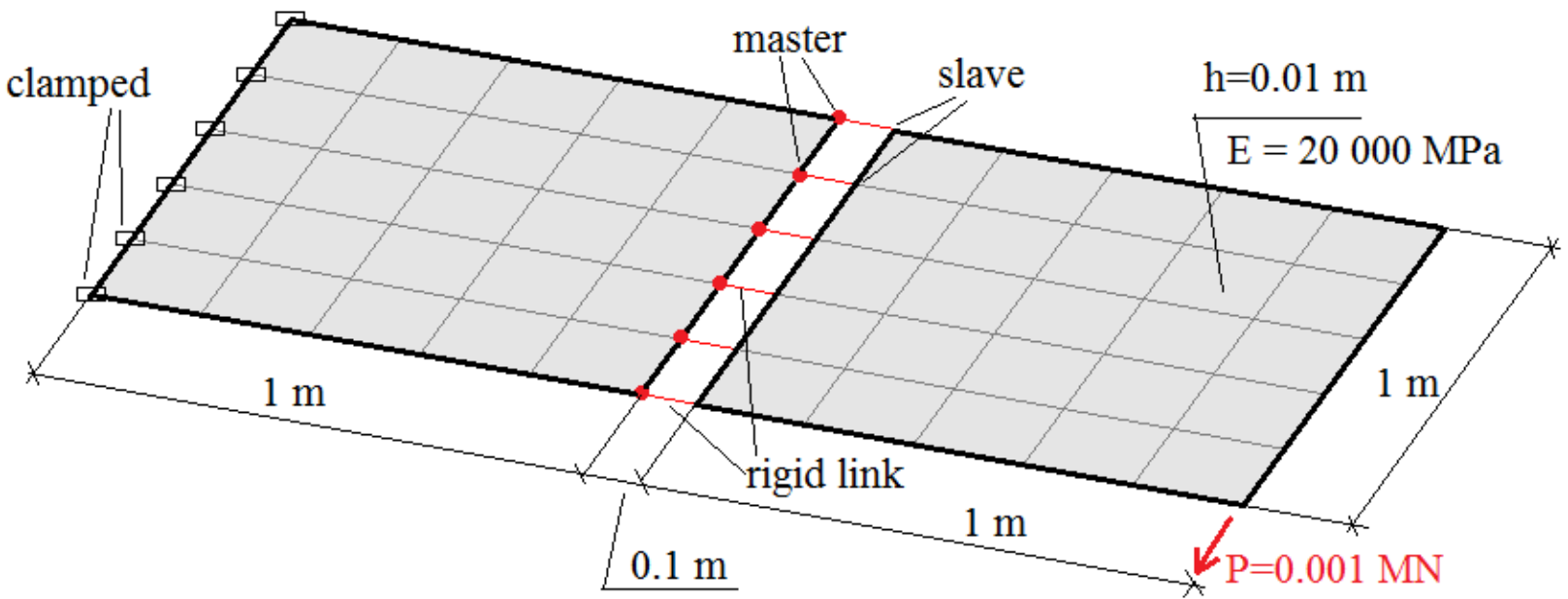

Figure 12. Two plates connected by rigid links.

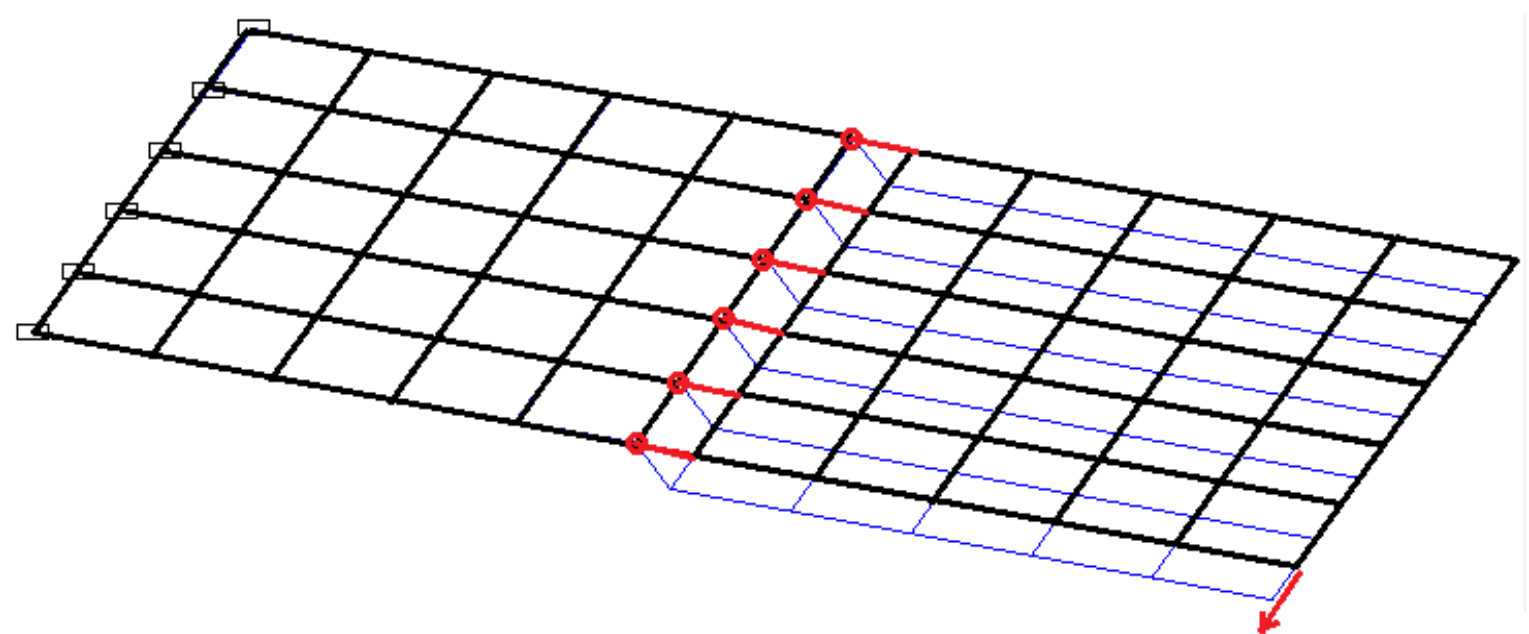

Figure 13. Displacements of the structure. Finite element MITC4.

Example 2. Two plates connected by rigid links are considered (Fig. 12). The displacements of this structure under the action of a concentrated force $\mathrm{P}$ acting in the plane of the plates are analyzed. The flat shell finite element MITC4 12 , as well as the quadrilateral finite element Q4 [11], are used.

The peculiarity of this problem is the fact that the finite element MITC4 does not have stiffness preventing the rotation relative to the normal to the middle surface (drilling rotation). Therefore, the global stiffness matrix contains zero rows and columns on the degrees of freedom corresponding to the drilling rotation.

The approach applied in 13, which lies in adding a small fictitious rigidity used when there is a difference between the average rotation angle of the finite element relative to the normal and the rotation angle in the current node, leads to the fact that the structure shown in Fig. 12 is close to a geometrically unstable one (Fig. 13). 


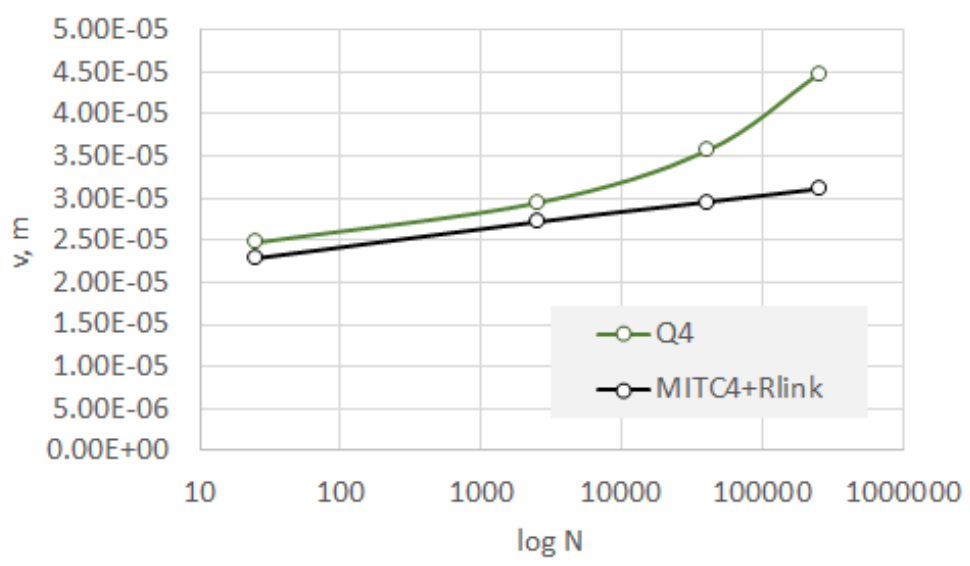

Figure 14. Dependence of the displacement $v, m$ on the number of mesh points $N$.

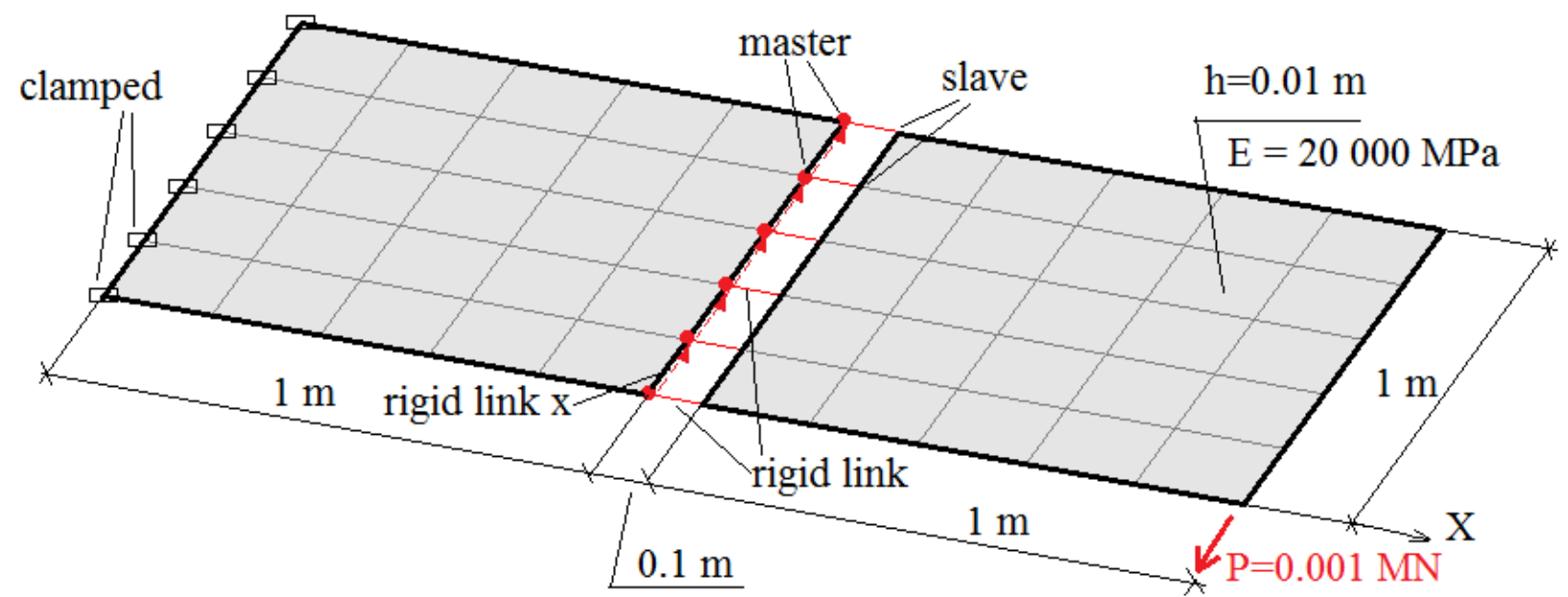

Figure 15. "Rigid link" connects a master node (indicated by a red dot) with a slave node in all degrees of freedom. "Rigid link $x$ " binds only the displacement $u$ along the OX axis, and the arrow is directed to the slave node.

When the finite elements Q4 11 are used (their bending stress-strain state is given in 9 , and the membrane stress-strain state is given in 10), the finite rigidities are on the "drilling rotation" degrees of freedom, therefore, the conditioning of the global stiffness matrix is much better, than in the MITC4 element. The experience of using the Q4 element in Robot 14, and in the author's research software has shown that the solution accuracy is satisfactory when coarse meshes are used in the model problems testing the torsion of a column connected to a floor slab, and bending of a deep beam under the action of concentrated bending moments in the corners 10 . However, at an unlimited refinement of the mesh, the above stiffness values tend to zero 1 therefore, the results obtained for the considered problem should be treated with caution.

Q4-curve in Fig. 14 shows this. Here $v$ is the displacement of the node in which the force is applied in the direction of its action, $\mathrm{N}$ is the number of mesh points. The design models with meshes $5 \times 5,50 \times 50,200 \times 200$ and $500 \times 500$ are considered. Beginning with a mesh $50 \times 50$ an intensive increase of displacement is observed. The results obtained for the case when the Rlink finite element was used ( $« \mathrm{~B} »$ method) coincide with the results of the «A» method up to 4 significant digits at GAM $=10000$.

In order to use the MITC4 elements, we must modify the design model. One possible solution is shown in Figure 15, the rigid links "rigid link $x$ ", binding only the translational displacements 


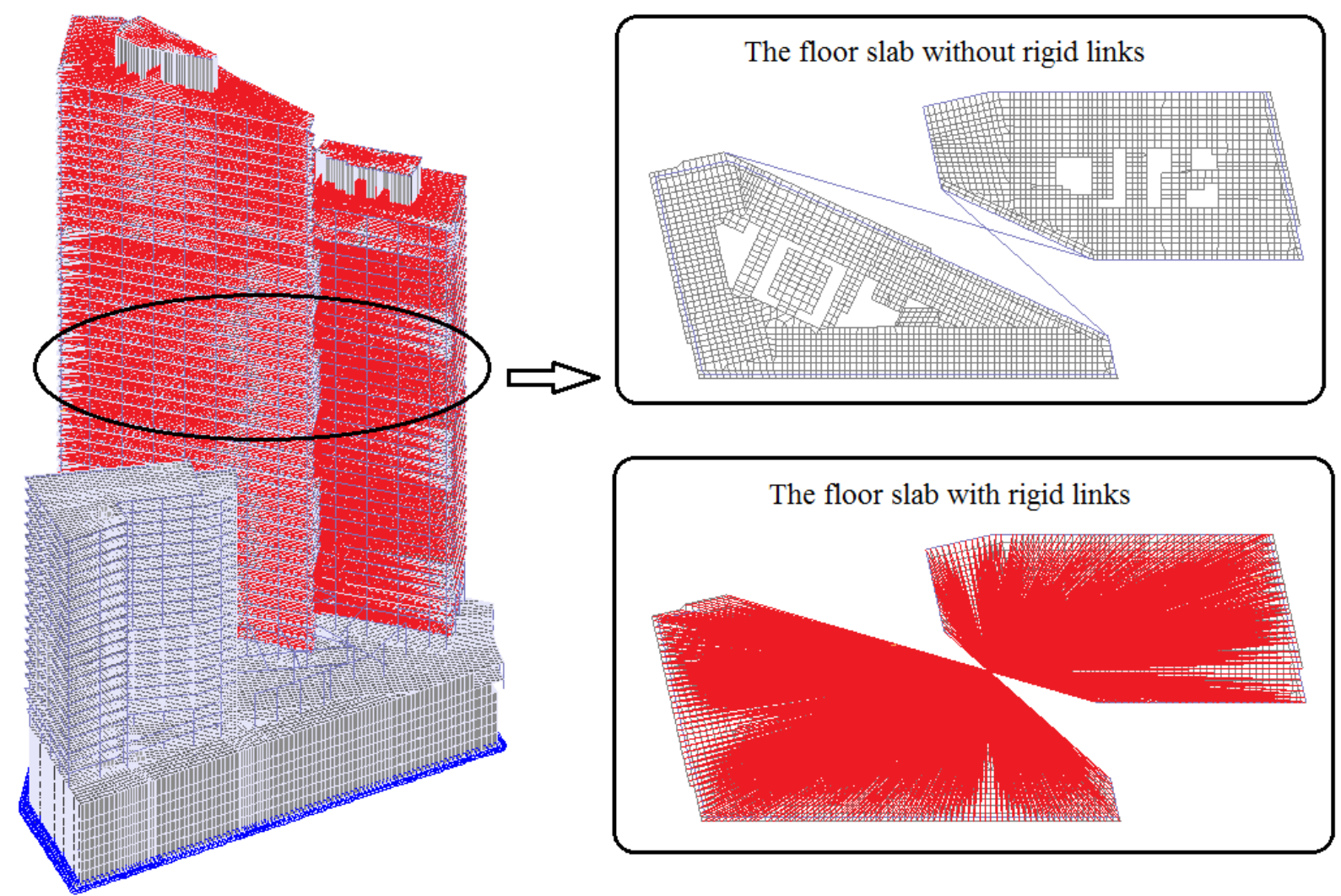

Figure 16. Design model of a high-rise building (1 275162 equations) and a fragment of a floor slab. Rigid links are used for modeling floor slabs as a rigid body in the plane of the slab.

$\mathrm{u}$ in the direction of the $\mathrm{OX}$ axis, are added in addition to the previously used rigid links "rigid link" connecting plates in all degrees of freedom. The master nodes are indicated by red dots.

The "rigid link $x$ " elements bind displacements $\mathrm{u}$ of two consecutive nodes. Thus, a "rigid angle" is formed in each master node, which involves the tension-compression and shear stiffness when this node is subjected to torsion relative to the normal.

The curve MITC4+Rlink presents the behavior of such model in Fig. 14. Unlike the previous design model which used the Q4 elements, displacement values $\mathrm{v}$ of the given design model do not diverge with the mesh refinement.

Thus, the advantage of the first model that uses Q4 elements is the absence of additional "rigid link $x$ " elements and a good conditionality of the system of linear algebraic equations. However, this design model enables to obtain acceptable results only on coarse meshes. The numerical solution diverges when the mesh is refined.
An undisputed advantage of the second design model is the convergence of the numerical solution. When the meshes are coarse, both models give similar results.

Example 3. The design model of a high-rise building (Fig. 16) taken from the SCAD Soft collection is considered. The dimension of the problem is 1275162 equations.

This building was erected in Moscow, so it was necessary to perform its strength analysis according to the requirements of the Moscow urban construction design code MGSN 4.19-05, which prescribes a seismic analysis for a 5- and 6-point earthquake. The floor slabs are considered as rigid bodies in their plane and their bending stiffness is assumed to be finite. In accordance with these requirements, the design model involves rigid links (Fig. 13), which restrict only horizontal translational displacements. 
Table 5. Error of the solution of the system of linear algebraic equations by PARFES 5, 6 and multifrontal method BSMFM 3, 4.

\begin{tabular}{|c|c|c|}
\hline Load case & $\begin{array}{c}\text { Error at the solution } \\
\text { by PARFES }\end{array}$ & $\begin{array}{c}\text { Error at the solution } \\
\text { by BSMFM }\end{array}$ \\
\hline 1 & $9.819427 \mathrm{e}-007$ & $5.839926 \mathrm{e}-009$ \\
\hline 2 & $1.340733 \mathrm{e}-006$ & $3.692731 \mathrm{e}-009$ \\
\hline 3 & $1.125980 \mathrm{e}-005$ & $1.818273 \mathrm{e}-008$ \\
\hline 4 & $8.232009 \mathrm{e}-006$ & $2.611328 \mathrm{e}-008$ \\
\hline 5 & $9.872282 \mathrm{e}-006$ & $1.815249 \mathrm{e}-008$ \\
\hline 6 & $7.377167 \mathrm{e}-006$ & $3.395874 \mathrm{e}-008$ \\
\hline 7 & $3.511916 \mathrm{e}-007$ & $7.428898 \mathrm{e}-010$ \\
\hline 8 & $2.993076 \mathrm{e}-007$ & $2.887699 \mathrm{e}-010$ \\
\hline 9 & $3.884085 \mathrm{e}-006$ & $4.464822 \mathrm{e}-008$ \\
\hline 10 & $4.262448 \mathrm{e}-006$ & $4.017364 \mathrm{e}-008$ \\
\hline
\end{tabular}

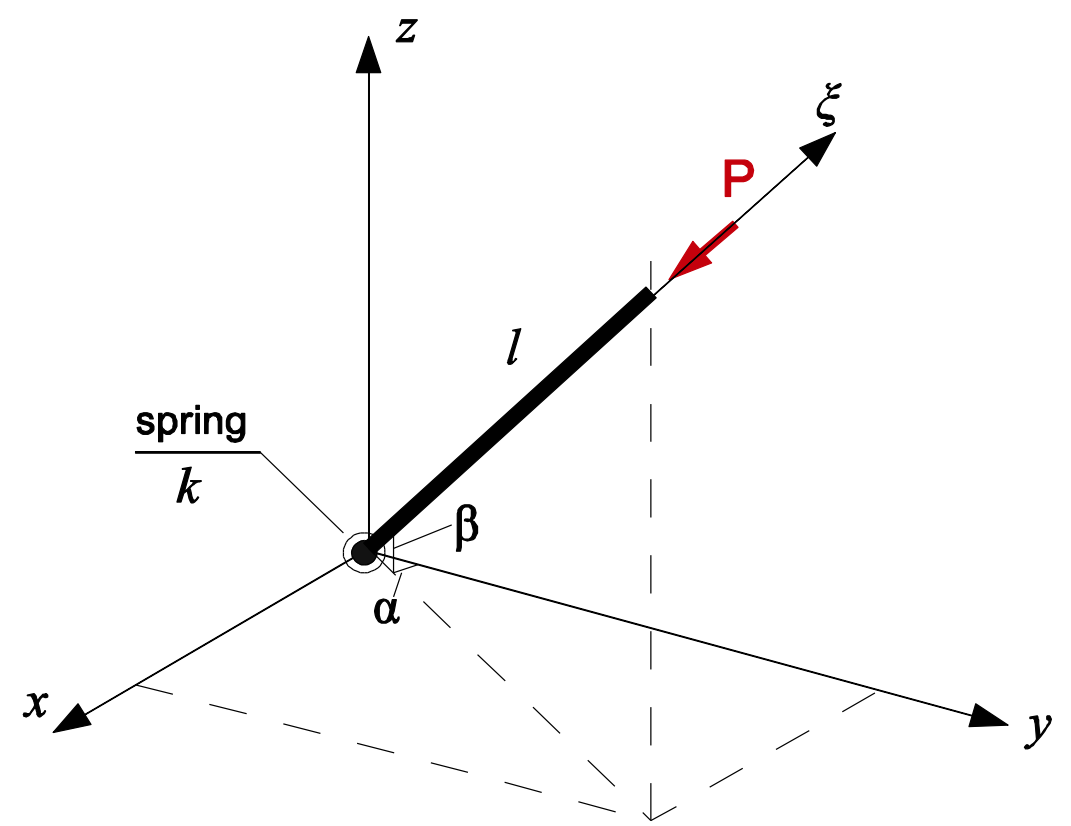

Figure 17. Hinged rigid rod under the action of an axial compressive force.

Multiple rigid links are intersected in the same master node, so the stiffness in the master node is accumulated during assembling when a method "B" is applied. The strategy for selecting the penalty parameter GAM is described in Section 4, expression (25), and is applied here. The solution error for the first ten load cases is given in Table 5. It should be noted that the multifrontal method BSMFM 3, 4 has proved to be more resistant to ill-conditioning than PARFES 5, 6 for the considered problem. It is probably due to the fact that the multifrontal method does not assemble a stiffness matrix entirely, and the assembly and decomposition are performed simultaneously. The METIS reordering 7 is used for both PARFES and BSMFM methods. The default values of GamMax and GamMin (10 000 and 100) are applied.

Example 4. A rigid rod of the length $l$, inclined to the OY axis at an angle $\alpha$ and to the XOY plane at an angle $\beta$, is considered. The rod has a spherical hinge support prohibiting translational displacements, in which each elastic spring of stiffness $k$ works at the rotation angles of the rod 


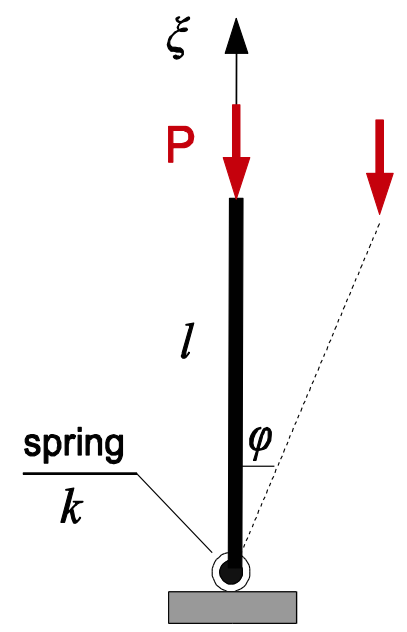

Figure 18. Transition of a rod to the deflected state during buckling.

at its deviation from the equilibrium position. The axial compressive force $\mathrm{P}$ is applied to the free end.

Figure 18 presents a drawing of a plane passing through the axis of the rod in the pre-buckling state and the axis of the rod in the deflected state caused by buckling.

Equilibrium condition of the rod in the deflected state: $k \varphi-\lambda_{c r} P l \varphi=0$, from where it follows that the parameter of the critical force is $\lambda_{c r}=P l / k$. Accepting $l=1 \mathrm{~m}, \alpha=60^{\circ}, \beta=$ $45^{\circ}, k=1 \mathrm{MN} \cdot \mathrm{m}, \mathrm{P}=1 \mathrm{MN}$, we obtain $\lambda_{c r}=1$. The rotation of the rod on the angles $\alpha$ and $\beta$ does not affect the value of the critical force, however, it leads to the fact that the matrix $\boldsymbol{\Omega}$ does not contain any zero entries. It enables to perform the testing in the most general form.

When using the finite element method, the rigid rod is modelled by the Rlink element and the springs are modeled by the elastic supports, working only at the rotation angles. Since the problem is spatial, we have obtained two mutually orthogonal buckling modes with multiple values of the critical force parameter $\lambda_{c r, 1}=\lambda_{c r, 2}=1$, which correspond to the above exact solution.

Example 5. The problem shown in Fig. 3 is considered. The exact value of the critical force is 1 :

$$
P_{c r}=\frac{3 E I}{l h} .
$$

The following values are accepted: $l=1 \mathrm{~m}, h=$ $1.5 \mathrm{~m}, E=200000000 \mathrm{kN} / \mathrm{m}^{2}, I=8.3333 \cdot 10^{-6}$ $\mathrm{m}^{4}$. The corresponding exact value of the critical force is $P_{c r}=3333.32 \mathrm{kN}$.

In the finite element model, the collar beam is divided into 10 finite elements of the plane frame, and the columns are modelled by the Rlink elements and $P_{c r}=3333.31$. If the collar beam is modelled by a single finite element of the plane frame, then $P_{c r}=3332.15 \mathrm{kN}$.

\section{CONCLUSION}

The proposed method of modeling rigid links has proved to be effective for solving the static and buckling problems of structures the design models of which contain rigid bodies $(14,15)$.

\section{ACKNOWLEDGMENTS}

The preparation of this work was supported by SCAD Soft IT company. 


\section{REFERENCES}

1. Perelmuter A.V., Slivker V.I. Numerical Structural Analysis. Springer Berlin Heidelberg, 2003.

2. Timoshenko S.P., Woinowsky-Krieger S. Theory of Plates and Shells. McGraw-Hill Book Company Inc., New York, 1959.

3. Fialko S. A Sparse Shared-Memory Multifrontal Solver in SCAD Software. // in: Proceedings of International Multiconference on Computer Science and Information Technology; October 20-22, 2007, Wisła, Poland, 3 (2008), ISSN 18967094, ISBN 978-83-60810-14-9, IEEE Catalog Number CFP0864E-CDR, pp. 277283, 2008.

4. Fialko S. The Block Substructure Multifrontal Method for Solution of Large Finite Element Equation SETS. // Technical Transactions 1-NP (8), 2009, pp. 175-188 (in Polish).

5. Fialko S. PARFES: A Method for Solving Finite Element Linear Equations on Multicore Computers. // Advances in Engineering software, 40(12), 2010, pp. 1256-1265.

6. Fialko S. Parallel Direct Solver for Solving Systems of Linear Equations Resulting from Finite Element Method on Multi-Core Desktops and Workstations. // Computers and Mathematics with Applications, 70, 2015, pp. 2968-2987.

7. Karypis G., Kumar V.A. Fast and High Quality Multilevel Scheme for Partitioning Irregular Graphs. Technical Report TR 95035, Department of Computer Science, University of Minnesota, Minneapolis, 1995.

8. George A., Liu J.W.H. Computer solution of sparse positive definite systems, New Jersey, Prentice-Hall, Inc. Englewood Cliffs, 1981.

9. Katili I. A New Discrete Kirchhoff-Mindlin Element Based on Mindlin-Reissner Plate Theory and Assumed Shear Strain Fields Part II: An extended DKQ Element for
Thick-Plate Bending Analysis. // Int. J. Num. Meth. Eng., 36, 1993, pp. 1885-1908.

10. Ibrahimbegovic A., Taylor R.L., Wilson E.L. A Robust Quadrilateral Membraine Finite Element with Drilling Degree of Freedom. // Int. J. Num. Meth. Eng., 30, 1990, pp. 445-457.

11. Fialko S.Yu., Ankyanec E.K. Vibrations of Thin Cylindrical Shells with Non-Stiff Connection Between Ribs and Paneling. In book: Shell Structures: Theory and Applications (Edited by: W. Pietraszkiewicz, C. Szymczak). Taylor \& Francis Group, London, 2006, pp. 315-317.

12. Bathe K.J. Finite Element Procedures. New Jersey, Prentice Hall, 1996.

13. Zienkiewicz O.C., Taylor R.L. The Finite Element Method, Fifth Edition, Volume 2: Solid Mechanics, Butterworth - Heinemann. 2000.

14. URL: http://www.robobat.pl/oprogramowanie/kon strukcje/autodesk-robot-structuralanalysis.html (last access - 8.07.2014).

15. URL: http://www.scadsoft.com (last access $-15.07 .2014)$.

Sergey Yu. Fialko, Professor, Dr.Sc., Department of Physics, Mathematics and Applied Computer Science, Cracow University of Technology; 24, ul. Warszawska, Kraków 31-155, Poland; tel. +48 1262820 00;

fax +48 1262820 71; e-mail: sergiy.fialko@gmail.com

Фиалко Сергей Юрьевич, профессор, доктор технических наук, кафедра физики, математики и прикладных компьютерных наук, Краковский политехнический университет; 24, ul. Warszawska, Kraków 31-155, Poland; тел. +48 1262820 00;

факс +48 1262820 71; e-mail: sergiy.fialko@gmail.com 